This item was submitted to Loughborough's Research Repository by the author.

Items in Figshare are protected by copyright, with all rights reserved, unless otherwise indicated.

\title{
Design of human surrogates for the study of biomechanical injury: a review
}

PLEASE CITE THE PUBLISHED VERSION

http://dx.doi.org/10.1615/CritRevBiomedEng.2013006847

PUBLISHER

Begell House, Inc.

VERSION

AM (Accepted Manuscript)

LICENCE

CC BY-NC-ND 4.0

REPOSITORY RECORD

Payne, Tom, Sean Mitchell, and Richard Bibb. 2013. "Design of Human Surrogates for the Study of Biomechanical Injury: A Review". figshare. https://hdl.handle.net/2134/11971. 


\section{Journal Paper - Critical Reviews in Biomedical Engineering}

Title: Design of Human Surrogates for the Study of Biomechanical Injury: A

\section{Review}

Thomas Payne, Dr. Séan Mitchell*, Dr. Richard Bibb

Wolfson School of Mechanical and Manufacturing Engineering, Loughborough University, Loughborough, Leicestershire, LE11 3TU, UK

Corresponding author.

Dr. Séan Mitchell

Office Address: Sports Technology Institute, 1 Oakwood Drive, Loughborough University, Leicestershire, LE11 3QF, UK

Tel: +44 (0)1509 564 804;

Fax: (0)1509 564820;

E-mail: S.R.Mitchell@lboro.ac.uk 


\begin{abstract}
Human surrogates are representations of living human structures employed to replicate "real life” injurious scenarios in artificial environments. They are used primarily to evaluate personal protective equipment (PPE) or integrated safety systems (e.g. seatbelts) in a wide range of industry sectors (e.g. automotive, military, security service and sports equipment). Surrogates are commonly considered in five major categories relative to their form and functionality: human volunteers, post mortem human surrogates, animal surrogates, anthropomorphic test devices and computational models. Each surrogate has its relative merits. Surrogates have been extensively employed in scenarios concerning "life threatening" impacts (e.g. penetrating bullets or automotive accidents). However, more frequently occurring non-lethal injuries (e.g. fractures, tears, lacerations, contusions) often result in full or partial debilitation in contexts where optimal human performance is crucial (e.g. military, sports). Detailed study of these injuries requires human surrogates with superior biofidelity to those currently available if PPE designs are to improve. The opportunities afforded by new technologies, materials, instrumentation and processing capabilities should be exploited to develop a new generation of more sophisticated human surrogates. This paper presents a review of the current state of the art in human surrogate construction, highlighting weaknesses and opportunities, to promote research into improved surrogates for PPE development.
\end{abstract}

\title{
Key Words
}

Biomechanics, Model, ATD, PMHS, Cadaver, Animal, Volunteer, Computational, PPE, Impact 


\section{Abbreviations}

ADAMS: Automatic Dynamic Analysis of Mechanical Systems

ATDs: Anthropometric Test Devices

AP: Anti-Personnel

CT: Computer Tomography

DADS: Dynamic Analysis and Design Software

EuroSID: Euro Side Impact Dummy

EMG: Electromyography

FEA: Finite Element Analysis

FEM: Finite Element Method

FFDs: Free Form Deformations

FLEX: Flexible Pedestrian Legform Impactor

FSL: Frangible Surrogate Leg

HURP: Human Use Review Panel

IED: Improvised Explosive Device

MRI: Magnetic Resonance Imaging

PCSA: Physiological Cross Sectional Area

PDEs: Partial Differential Equations

PMHS: Post Mortem Human Surrogate 
PPE: Personal Protective Equipment

SIMM: Software for Interactive Musculoskeletal Modelling

THOR: Test device for Human Occupant Restraint

TRL: Transport Research Laboratories

VIMS: Virtual Interactive Musculoskeletal System

WorldSID: World Side Impact Dummy 


\section{INTRODUCTION}

In the field of injury biomechanics, the primary goals are concerned with replicating "real life" injurious scenarios in a laboratory environment through an understanding of the mechanisms of injury, characterisation of human response to loading conditions and development of protective methods to prevent injury occurrence or limit severity ${ }^{1}$.

Human surrogates attempt to provide an artificial representation of a living human and thus offer a means of achieving the above stated goals. For any surrogate the ultimate aim is 'biofidelity', which is the term used to describe the exactness with which a given surrogate approximates the behaviour of a human when subjected to comparable loading condition ${ }^{2}$.

There are several industries that utilise surrogate to improve their understanding of human behaviour and response to different environmental conditions. Human surrogates arguably have the most widespread usage within the automotive industry. Approximately 40,000 people suffer fatal injuries in the United States (US) each year as a result of automotive crashes. This is also a serious issue in the European Union (EU); in 2001 there were approximately 40,000 deaths and 1.6 million casualties as a result of road traffic accidents. Human surrogates are essential in research and development of vehicle safety measures ensuring the safety of vehicle occupants and pedestrians ${ }^{3,4}$. They are generally utilised in two methodologies: dynamic impact testing and determination of human factors for restraint systems (e.g. compliant steering wheels, force limiting seatbelts and more efficient airbags) and evaluation of vehicle interiors.

Surrogates are further utilised to consider pedestrian impacts; in the European Union over 7000 pedestrians and 2000 cyclists are killed every year in road accidents ${ }^{4}$. Vehicle manufacturers use surrogates to determine human impact response and attempt to reduce the risk of injury through intervening measures such as adaptation of car bumpers. 
The application of human surrogates in the medical industry has become significantly more widespread in recent years. The most prevalent usage of surrogates in the medical industry is through simulation of orthopaedic surgical procedures such as joint replacements or osteotomies $^{5-8}$. Vast arrays of models of human anatomy are also used in training medical personnel in a wide variety of invasive and non-invasive medical procedures. Medical training models range from the crude to the very sophisticated depending on the nature of the task and risk involved.

The military use surrogates to assess the effectiveness of PPE in vitro. Owing to the nature of the armed conflict, debilitating and often fatal injuries are a common occurrence. In the recent conflicts in Iraq and Afghanistan, the improvised explosive device (IED) has been the most prevalently used weapon ${ }^{9,10}$, over $44 \%$ of all U.S. military hostile casualties and wounded were attributed to a weaponry explosive device ${ }^{11}$. Hence the primary areas of concern for military research are typically from Anti-Personnel (AP) landmines and penetrating bullet impacts ${ }^{9-13}$. Human surrogates aim to provide a basis for understanding the mechanisms of critical military injuries and serve as an aid for testing PPE under extreme loading conditions.

Human surrogates are also used in the sports PPE and garments domain. PPE is a requirement in many contact sports with the obvious primary goal being the safety of the athlete. PPE is usually designed to prevent impact injuries and typically performs one or more of the following functions: impact energy attenuation; acceleration management; load distribution; force limitation; and even measurement and registration of impacts ${ }^{14}$. However, with performance margins becoming ever smaller there is an increasing desire to gain a competitive edge. In an ideal scenario all PPE should enable optimal performance whilst preventing impact injury, since these aspirations may be conflicting a trade-off is required to engineer products with due consideration to both safety and performance of the user. 
The primary application of surrogates within the sporting domain is for injury phenomena testing especially those concerned with impacts. Surrogates are being increasingly used to represent a human during PPE testing to understand the forces transmitted through the PPE and experienced by the surrogate.

However there are further issues pertaining to the comfort and fit of the PPE on the user for which a surrogate has applicability ${ }^{14}$. The relative position of the garment with respect to the contours of the human anatomy is an aspect that needs to be considered to obtain a comfortable fit. This shape and fit must be maintained throughout motion and when the garment is flexed, remaining proximal to the user providing a high level of protection and comfort. Other comfort and fit performance criteria relate to issues such as moisture and thermal management as these factors are performance inhibitors in certain sporting contexts $^{15,16}$

Surrogates have differing requirements between industrial applications. In sports, permanent absence from competition is the critical severity measure; professional athletes receive substantial sums of money to perform on a regular basis, and therefore absence bears a significant financial burden for their employers.

Typically most conventional surrogates are concerned with very serious or life threatening injuries such as penetrating bullet impacts or vehicle impacts. In sports, injuries such as lacerations, contusions, and fractures are more prevalent, debilitating and so serious concerns. A set of important criteria are proposed for sports impact surrogates. These are not absolute requirements, sports surrogates need to address several design issues to a degree necessary to evaluate PPE performance and injury realistically when considering pertinent injurious sporting impacts. 
- Biofidelic exterior human geometries, to ensure that PPE is attached and aligned correctly before impact.

- Biofidelic inertial properties, ensuring that the surrogate recoils in an accurate manner on impact.

- Tissue structure biofidelity, the surrogate needs to represent the key human structural elements so specific injury outcomes can be explored.

- Tissue impact response biofidelity, the structures should have comparable strength and stiffness properties to approximate human behaviour on impact.

- Instrumentation capabilities, to provide accurate feedback mechanisms to correlate the impact parameters to specific injury outcomes.

- Durable, capable of providing consistent results from repeated impacts.

The above stated issues must be considered relative to specific sporting scenarios. Surrogates more tailored to the prevalent injury methods present the opportunity to provide a better, more sensitive description of the injury event and PPE effectiveness.

Common sports impacts occurring to regions of the body where the opposition player wears PPE have been recorded using data from academic sources. The impact parameters listed in Table 1 provide an estimation of the conditions experienced by players when involved in the activity. The momentum and impact energy parameters provide an indication of the impact intensity which can be used to make relative comparisons between impacts in different sports.

Safety standards provide set criteria on how PPE must perform under prescribed test conditions, providing a baseline for comparisons between designs. The test conditions of associated standards have been listed in table 2 in the same format as the actual 'in play' impact parameters 
Table 1 - Estimations of the Conditions Experienced in 'In Play' Sport Impacts

\begin{tabular}{|c|c|c|c|c|c|}
\hline \multirow[t]{2}{*}{ Scenario } & \multirow[t]{2}{*}{ Description } & \multicolumn{4}{|c|}{ Actual Impacts } \\
\hline & & $\begin{array}{l}\text { Effective Impactor } \\
\text { Mass }(\mathrm{kg})\end{array}$ & Impact Velocity $\left(\mathrm{ms}^{-1}\right)$ & $\begin{array}{c}\text { Estimation of } \\
\text { Maximum 'In Play' } \\
\text { Momentum }\left({\left.\mathrm{kg} . \mathrm{ms}^{-1}\right)}\right.\end{array}$ & $\begin{array}{c}\text { Estimation of } \\
\text { Maximum 'In Play' } \\
\text { Impact Energy }(J) \\
\end{array}$ \\
\hline $\begin{array}{l}\text { Rugby Shoulder } \\
\text { Tackle }\end{array}$ & $\begin{array}{l}\text { Frontal impact from the shoulder of the tackling } \\
\text { player into the frontal thigh region of the } \\
\text { opposition ball carrier. }\end{array}$ & $\begin{array}{l}\text { 100-230 (1- } 2.3 * \text { Body } \\
\text { Weight, assuming } \\
\text { 100kg player })^{17-19}\end{array}$ & $\begin{array}{c}\text { 3, tackler, } 7.5 \text {, ball } \\
\text { carrier (estimated from } \\
\text { video data) })^{20} \\
\end{array}$ & $2.42 \times 10^{3}$ & $1.27 \times 10^{4}$ \\
\hline $\begin{array}{l}\text { American } \\
\text { Football Tackle }\end{array}$ & $\begin{array}{l}\text { Frontal impact involving upper body regions of } \\
\text { tackler and opposition. }\end{array}$ & $\begin{array}{l}\text { 123-182(1.23-1.82* } \\
\text { Body Weight, } \\
\text { assuming 100kg } \\
\text { player) }\end{array}$ & $1.72-2.18$ & $3.96 \times 10^{2}$ & $4.32 \times 10^{2}$ \\
\hline $\begin{array}{l}\text { Cricket Ball } \\
\text { Impact }\end{array}$ & $\begin{array}{l}\text { Projectile impact from a cricket ball launched at } \\
\text { high velocities at the batsman. }\end{array}$ & $0.155-0.163$ & $34.6^{22}$ & 5.5 & 95.2 \\
\hline $\begin{array}{l}\text { Field Hockey } \\
\text { Ball Impact }\end{array}$ & $\begin{array}{l}\text { Projectile impact from a field hockey ball } \\
\text { launched at high velocities at the opposition } \\
\text { player. }\end{array}$ & $0.155-0.163$ & $40^{23}$ & 6.4 & $1.28 \times 10^{2}$ \\
\hline $\begin{array}{l}\text { Football Stud to } \\
\text { Shin Impact }\end{array}$ & $\begin{array}{l}\text { Frontal impact from the studs of the tackler to } \\
\text { the frontal shin region of the ball carrier from a } \\
\text { sliding tackle. }\end{array}$ & $\begin{array}{l}4.58 \text { (foot and lower } \\
\text { leg) }\end{array}$ & $1.2-2.5^{25}$ & 11.5 & 14.3 \\
\hline $\begin{array}{l}\text { Football Shin } \\
\text { on Shin Impact }\end{array}$ & $\begin{array}{l}\text { Horizontal impact between the frontal surfaces } \\
\text { on the shin region of both the tackler and ball } \\
\text { carrier resulting from a swinging leg contact. }\end{array}$ & $\begin{array}{l}4.58 \text { (foot and lower } \\
\text { leg) }\end{array}$ & $16^{26}$ & 73.3 & $5.86 \times 10^{2}$ \\
\hline
\end{tabular}


Table 2 - Test Conditions Prescribed in Safety Standards

\begin{tabular}{|c|c|c|c|c|c|c|c|}
\hline \multirow[t]{3}{*}{ Garment } & \multirow[t]{3}{*}{ Description } & \multicolumn{6}{|c|}{ Test Conditions } \\
\hline & & \multirow{2}{*}{$\begin{array}{l}\text { Effective } \\
\text { Impactor } \\
\text { Mass }(\mathrm{kg})\end{array}$} & \multirow{2}{*}{$\begin{array}{l}\text { Impact } \\
\text { Velocity } \\
\left(\mathrm{ms}^{-1}\right)\end{array}$} & \multicolumn{2}{|c|}{ Maximum Estimation of Momentum } & \multicolumn{2}{|c|}{$\begin{array}{l}\text { Maximum Estimation } \\
\text { of Impact Energy }\end{array}$} \\
\hline & & & & $k g \cdot m s^{-1}$ & $\begin{array}{l}\text { \% Difference } \\
\text { from 'in play' } \\
\text { estimate }\end{array}$ & $J$ & $\begin{array}{l}\text { \% Difference } \\
\text { from 'in play' } \\
\text { estimate }\end{array}$ \\
\hline $\begin{array}{l}\text { Football Shin } \\
\text { Guards (Stud } \\
\text { Impact) }\end{array}$ & $\begin{array}{l}\text { BS EN 13061:2009 "Protective clothing - Shin guards for } \\
\text { association football players - Requirements and test } \\
\text { methods" } 27\end{array}$ & $1.0 \pm 0.01$ & $5.4 \pm 0.2$ & 5.4 & -53.0 & 14.6 & +2.1 \\
\hline $\begin{array}{l}\text { Football Shin } \\
\text { Guards (Blunt } \\
\text { Impact) }\end{array}$ & $\begin{array}{l}\text { BS EN 13061:2009 "Protective clothing - Shin guards for } \\
\text { association football players - Requirements and test } \\
\text { methods" } 27\end{array}$ & $1.0 \pm 0.005$ & $2 \pm 0.05$ & 2.0 & -97.3 & 2.0 & -99.7 \\
\hline $\begin{array}{l}\text { Cricket Leg } \\
\text { Protectors }\end{array}$ & $\begin{array}{l}\text { BS 6183-3:2000 "Protective equipment for cricketers - } \\
\text { Part 3: Leg protectors for batsmen, wicket keepers and } \\
\text { fielders, and thigh, arm and chest protectors for batsmen" } \\
28\end{array}$ & $2.5 \pm 0.1$ & $2-5.66$ & 14.2 & +157.2 & 40 & -58.0 \\
\hline $\begin{array}{l}\text { Field Hockey } \\
\text { Chest Protector }\end{array}$ & $\begin{array}{l}\text { BS EN 13546:2000 "Protective clothing - Hand, arm, } \\
\text { chest. Abdomen, leg, foot and genital protectors for field } \\
\text { hockey goal keepers and shin protectors for field players - } \\
\text { Requirements and test methods" } 29\end{array}$ & $2.5 \pm 0.1$ & $2-6.32$ & 15.8 & +146.9 & 50 & -60.9 \\
\hline
\end{tabular}


Impact surrogates used in sports PPE test standards typically embody poor approximations of human tissue structures. In many instances both the striking element and target component (anvil) used in standards can be considered as human surrogates and as such should aim to represent the mass, shape and stiffness of the relevant human tissue.

The surrogate anvils used in the test standards commonly use simple geometric shapes with approximate outer surface curvatures relevant to the specific human body segment; they are typically constructed from steel and are rigidly attached to a massive concrete base. This provides a poor representation of the structures in the human body; the differences in the anvil will affect the manner in which the surrogate responds to impact, there are also fixed constraints on the anvil, which prevent the surrogate recoiling in a manner similar to that experienced in the body.

The velocities that the tests are conducted at are also unrepresentative of those estimated in play, particularly when considering sports where projectile impacts are prevalent. In these sports scenarios PPE is tested at velocities significantly below those actually experienced, which leads to poor consideration of the impact intensities.

The discrepancies between the strikers, anvils and 'in play’ performance replication characteristics mean that the conditions that the PPE is being tested at differ greatly from actual in play impact intensities. The development of superior impact surrogates that are more representative of human structures, which can be tested in more characteristic environments under more closely matching impact conditions will provide a better and more thorough evaluation of PPE suitability.

The purpose of this paper is to review the design of human surrogates in injury prevention and PPE evaluation. Methodologies previously used to represent human impact behaviour are discussed and their relative merits evaluated with reference to the requirements for more 
sophisticated surrogates in relevant applications. Potential future developments in each of the respective surrogate modelling fields are discussed and recommendations for the direction of associated research in the injury biomechanics domain given.

\section{APPLICATIONS OF SURROGATES IN INJURY BIOMECHANICS}

Five different types of surrogate are typically used in injury biomechanics research. They can be broadly categorised into two groups: organic surrogates (human volunteers, post mortem human subjects, and animal surrogates) and artificial surrogates (synthetic (physical) surrogates and computational (virtual) surrogates).

\section{A. Organic Surrogates}

\section{Human Volunteers}

Human volunteers as representative samples of a target demographic group present a key testing resource in impact biomechanics research. Studies utilising surrogates of this type have been conducted for many years to determine in vivo human injury response; one of the first human volunteer studies published was in 1954 by John Stapp, in which military personnel were tested through rapid decelerations from a rocket sled to simulate an aircraft crash.

The primary advantage of using volunteers is that they allow researchers to consider the in vivo response of a living human without having to make assumptions about or approximations of the internal structural tissue composition and physiology. Studies generally involve determining injury epidemiology from vehicle crash occupants or from laboratory based experiments; however both of these approaches have severe practical limitations ${ }^{30}$. 
Laboratory test experiments must be performed at non-injurious levels of exposure, below the pain threshold in compliance with the Nuremburg Code of 1947 and the Helsinki Declaration of 1964 revised in World Medical Association (2008) ${ }^{31}$, which provides ethical guidelines for human experimentation. In addition proposed testing protocols must be reviewed by an international review board to determine whether it meets all legal and ethical standards ${ }^{2,32}$. This severely limits the nature of testing that can take place and makes the testing more complex and expensive to perform.

Further practical limitations include the lack of direct measurements that can be taken as most instrumentation must be non-invasive to comply with ethical guidelines. Consequently internal loads must generally be inferred from measured external parameters rather than directly measured ${ }^{2}$. There is also decreased control and repeatability in testing humans as they are greatly inhomogeneous and as such there is considerable variability in and between trials. This leads to a difficulty in determining accurate relations between external loading parameters and specific injury mechanisms or phenomena. Similarly, there are issues in deriving relationships from different impact conditions (e.g. studies testing with low impact loads cannot be used to describe human response when subject to injurious loads).

Nevertheless laboratory testing has been instrumental in understanding the physiological human impact response, specifically through considerations such as muscle tonicity and activation levels that cannot be considered accurately on other surrogates.

Epidemiological studies of crash occupants are also inherently inaccurate; retrospective studies make it impossible to control the setting or collect sufficiently detailed information about the crash loading environment ${ }^{30}$. The lack of knowledge of the loading environment generally limits the utility of these studies as it is extremely difficult to define relationships with injury mechanisms. 
There is a large body of literature from tests conducted on human volunteers that has provided invaluable information about human response. However, it can be argued that human volunteers cannot be described as a surrogate in the field of injury biomechanics as they provide an exact representation of the target body, and hence are not providing an approximation of living humans. There is an overlap between the humans and artificial surrogates whereby much of the information required for the development of artificial surrogates is facilitated through testing of human volunteers, which has been noted in subsequent sections. This is well exemplified by Hyrsomallis et al. ${ }^{33}$ who conducted a series of drop tests using geometries representative of a cricket ball from various heights onto instrumented human volunteers. The data was used in the validation of a synthetic model.

A representative sample of human volunteers that could be tested to injurious levels and invasively measured would present the ultimate testing medium for sports PPE. However the severe constraints and extensive legislation that must be adhered to limit the nature of testing that can be performed and hence the usefulness of the surrogate type.

In a sports domain, human volunteers have their greatest utility through real play performance replication scenarios to determine the conditions experienced by the impacted body in an injury scenario. For example, Halkon et al. ${ }^{21}$ studied the peak forces in a shoulder on thigh tackle when an American Football player strikes a tackle bag. 


\section{Post Mortem Human Subjects}

Post mortem human subjects (PMHS) also known as cadavers were first introduced in the field of injury biomechanics in the $19^{\text {th }}$ century $^{34,35}$ and have since been widely used to characterise human impact responses ${ }^{2}$.

PMHS can be tested through a variety of different methods. However, in general whole body tests are conducted through an impact sled test, whilst local tests are conducted using a linear impactor, pendulum or falling weight ${ }^{32}$. Body regions are instrumented to provide both a direct (tissue damage) and indirect measure of impact force and injury prediction.

Accelerometers are generally attached directly to the bone, and the surface usually contacted by these regions is frequently backed by load cells to measure the impact force. Pressure transducers are sometimes used in re-pressurised blood vessels and markers are used to track body segments with high speed video ${ }^{32}$. However the predominant means of injury evaluation is through autopsy based procedures to assess visible damage to tissues, which requires trained medical staff to determine the extent of injuries ${ }^{36,37}$.

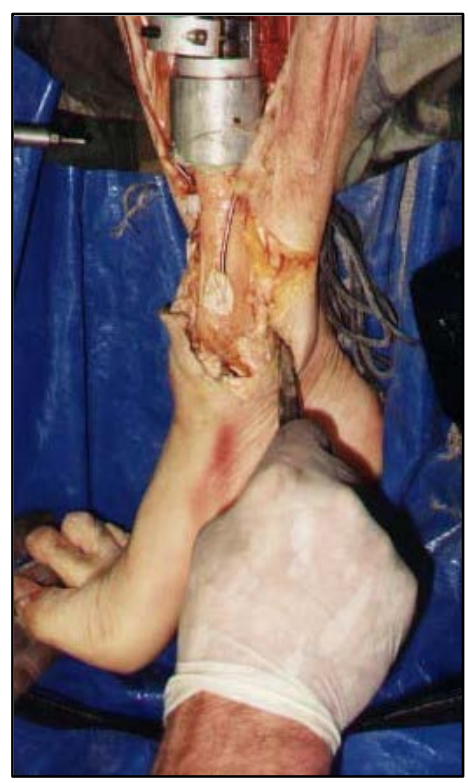

Figure 1 - Autopsy of an Instrumented PMHS Lower Leg (Photos courtesy of Allen-Vanguard Corporation, testing conducted through the US LEAP program) ${ }^{38}$ 
The key strength of PMHS is that they are exact geometrical and anatomical representations of the human tissue structures being tested ${ }^{39,40}$; there is currently no artificial substitute that can model the complexities of the human anatomy as accurately ${ }^{32,37,41}$. This makes them extremely useful in determining the extent of tissue damage under injurious impacts.

Despite this a key disadvantage associated with the use of PMHS concerns the lack of physiological response. The surrogates do not possess any cardiovascular activity and hence tissues remain unpressurised. There is also no neurological activity which causes an absence of reflexive response, which greatly affects their behavioural response and thus diminishes biofidelity ${ }^{2,36,42,43}$. Although PMHS contain a great deal of tissue complexities, the structures are flaccid and do not represent the tonicity of living human tissues.

PMHS are biological structures and hence there is a limited time period before decomposition processes such as autolysis and rigor mortis occur, which dramatically changes their mechanical properties ${ }^{44}$; Van Ee et al. ${ }^{45}$ noted that failure stresses significantly decreased following decomposition. After these processes have occurred PMHS are essentially atonal and unable to simulate resting muscle tone and contraction of living humans ${ }^{2}$. This is essential feature when testing in many industries, for example, it has been determined that more than $50 \%$ of occupants in frontal crashes engage in bracing behaviour ${ }^{46,47}$. The manner in which these post mortem changes affect responses is not fully understood and consequently data from human volunteers is often used to provide more accurate representations of human responses ${ }^{48}$.

Several different techniques have been used to preserve cadavers and extend their useful condition. Embalmed PHMS were used extensively as a means of preserving specimens; however, the process has been largely abandoned due to the artificially inaccurate tissue properties generated such as excessive tissue rigidity, limited joint ranges of motion, and 
modified ultimate strength of embalmed tissue ${ }^{44,49}$. Similarly freezing PMHS specimens has been shown to increase their useful life; however, additional facilities are required for the process, which makes it more complex and expensive. In addition, undesirable damage is caused to the tissue structure during the freezing and thawing process, which has been shown to decrease the failure strengths of the tissue ${ }^{50-52}$. Researchers have also attempted to restore some physiological function of the body through processes such as pressurising the cardiovascular systems or electrically stimulating muscles; however, these must be performed in the limited time scale before post mortem changes occur ${ }^{53}$.

Preserving a PMHS is difficult and often detrimental to the properties of the tissue and thus to most effectively use PMHS they should be tested shortly after death of the subject. This introduces further issues regarding the availability of PMHS specimens, as test studies often require numerous specimens, which can be considered to be practically unobtainable without preserving the PMHS in some manner. Generally, for studies in the field of injury biomechanics, comparable PMHS are required, however variations in age, gender, and anthropometry make this an increasingly difficult if not impossible task.

Due to ethical and social acceptance issues there are often difficulties associated with obtaining PMHS specimens ${ }^{32,43,54,55}$, and the age of available specimens is generally biased towards the elderly population. In injury biomechanics research, PMHS below the age of 70 are generally required ${ }^{32}$; the 'Association of Anatomy Chairmen' ethical guidelines stipulate that the age range of the subjects must be between 19-70 years. This frequently leads to a wide variation in the anthropometric and mechanical properties of the specimens; for example, cortical bone strength and has been shown to decreases significantly with age, which makes specimens significantly more susceptible to fracture ${ }^{56,57}$. Furthermore younger PMHS are generally required for females because of the potential changes in bone mineral density and strength of the skeleton after the menopause $e^{32,37}$. Consequently, it is unlikely that 
the age and medical history of the PMHS used in experimental studies would be representative of an athletic population, and an elite athletic population in particular $2,32,43,58$. Limitations in the availability of representative PMHS dictate that specimens are often impacted multiple times; however the PMHS become damaged through testing and injury tolerances and response corridors consequently vary between trials ${ }^{2,44}$.

PMHS are treated as a level 2 biohazard and therefore require specialised facilities, protocol and personnel when handling human tissue, which add both cost and complexity to the experiments $^{36,37,44,54,59}$. Furthermore there is a high cost in bio-contamination safeguards required for the handling and disposal of human biological material ${ }^{43}$. For example, Shaw et al. ${ }^{48}$ required approval from their organisations 'Human Use Review Panel' (HURP) and all personnel involved in PMHS were required to read and sign 'Ethical Treatment of Human Surrogate Forms'; furthermore, screening of blood for Hepatitis A, B, C, and HIV was conducted on each PMHS prior to acceptance into the research program. In general, host nations legislation will constrain organisations or individuals acceptable use and treatment of PMHS, for example, in the UK, the Human Tissue Act 2004 (c. 30) ${ }^{60}$ would apply and a licence would be required adding further delay and cost to any such research.

Nevertheless, PMHS continue to make an important contribution to our understanding of human injury response. The data collected from PMHS is often used to validate artificial surrogates and determine the injury response criteria. For example, tests have been performed on PMHS lower leg specimens to provide validation data for both synthetic and numerical models ${ }^{61,62}$. Kajzer et al. ${ }^{63,64}$ performed a series of tests on PMHS to study the response of the knee in lateral dynamic shear and lateral dynamic bending (Fig. 2), which has since been used as a critical piece of human response literature from which to validate artificial surrogates. 


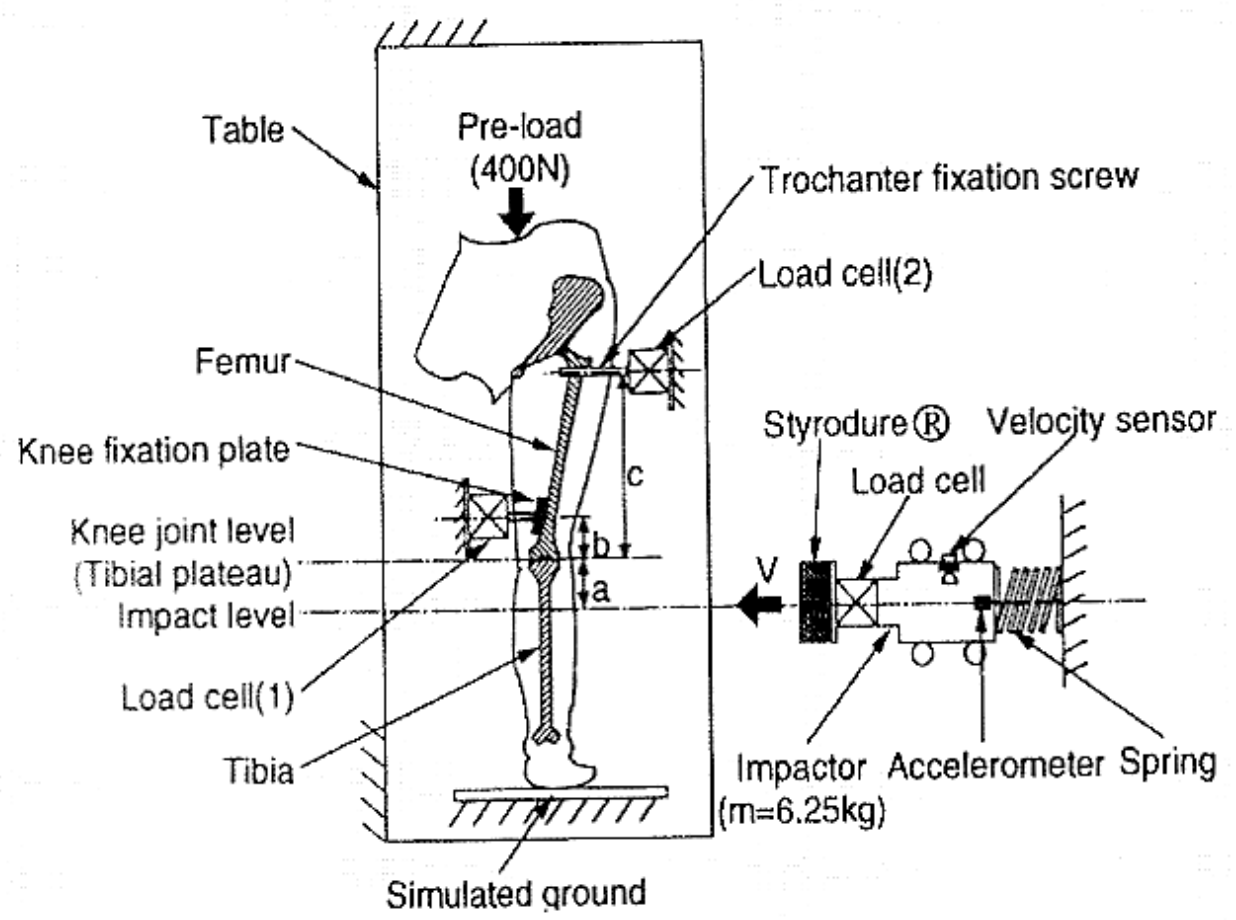

Figure 2 - Lateral Dynamic Shear Testing Configuration "Reproduced by permission of The Stapp Association." 64

Heald \& Pass ${ }^{65}$ considered the fracture velocities and severity index of cadaver head specimens when impacted with high strain rate projectiles from different ball sports. This research has been used to better inform the risk of sustaining injury and the effectiveness of synthetic surrogates as predictors.

When assessing the applicability of PMHS for use in sports injury assessment, their key advantage is that they contain all of the complex interacting structures present in the human body. They also provide a good description of material properties, geometries and inertial properties, although post mortem structural changes (e.g. lack of muscle tonicity and reflexive response) lower the biofidelity of these desirable properties. However, a key limitation is that that the tissue properties alter after impact, which makes them impractical and unreliable as a multi-use surrogate. Another major limitation behind the use of PMHS in a sporting context is the difficulty in embedding instrumentation, which will artificially 
change tissue response characteristics. Also issues regarding availability, ethical and institutional protocols make PMHS unfeasible for long term, multiple use testing.

The greatest utility of PMHS in sports injury assessments are related to testing of injurious impacts where a single damaging impact will be conducted. They are useful in limited passive applications where the lack of tonicity is either preferable or acceptable; however they would only be beneficial in sports applications in these contexts if restrictions for use permit and these restrictions don't make testing impractical. For example, determination of the fracture thresholds for high strain rate loading of the cranial bones from a cricket ball impact. When considering a single impact test, they currently present the only ethically acceptable and feasible way to get structural definition at this level of detail.

\section{Animal Surrogates}

Animals have been extensively used in injury biomechanics research for many decades; their use continues to the present day.

The primary advantage of animal surrogates is that they provide the closest living approximation to humans. Given the ethical issues associated with inducing injury in humans, anaesthetised animals present the only source for obtaining behavioural information for a single body region permitting the ability to follow the pathophysiologic response data following an injury ${ }^{2,32}$.

Animal cadaver surrogates are also used in certain applications where it would be grossly unethical to use living animals (e.g. blast surrogates for AP landmines). Animals with comparable human structures (e.g. primates) are difficult to use due to ethical concerns, therefore animal cadavers from domesticated animals commercially farmed and killed for food represent a less complex and expensive alternative. However, as with PMHS, the issues 
with animal cadaver surrogates are primarily concerned with the absence of physiological response present with live animals ${ }^{43}$. Testing using animal cadavers can however be employed to determine relationships between the behaviour of PMHS and living humans, as comparisons can be made between the differences present between living and dead animals $^{40,66}$.

Few animals have bone structures that are comparable in size and geometry to that of humans ${ }^{43}$. Rats, primates, rabbits and pigs are most commonly used for specific body parts; however, they all have obvious anatomical and physiological differences with human subjects that lead to inaccuracies in data interpretation. For example, considering the limbs used for locomotion, most animals used in injury biomechanics research are quadrupeds that walk on their toes whilst humans are upright bipeds, which inevitably affect their load distributions and measures the species has undertaken to accommodate movement (e.g. the calcaneus bone does not have to withstand axial loading ${ }^{57}$ ). This affects factors such as stride lengths, joint angles and torques from which erroneous assumptions can be made ${ }^{67}$. The data is often scaled so that it can be applied to humans due to differences in anatomy and level of tolerance between animals and humans; however this conveys its own associated inaccuracies ${ }^{32}$.

The great apes represent the most anatomically and physiologically similar species to humans due to their similar skeletal components and arrangement of internal organs ${ }^{68}$. However, due to the highly developed cognitive and behavioural characteristics present in great apes, ethical concerns have led to restrictions and bans in a large number of European countries ${ }^{2}$.

There are strict ethical guidelines and legislation governing testing of animals in the most developed countries. For example, in the US testing is governed by the 'Laboratory Animal Welfare Act of 1966 (P.L. 89-544), ${ }^{69}$; in the UK, testing is governed by The Animal Welfare Act 2006 (c 45), ${ }^{70}$. In addition, institutions performing experiments must create an 
'Institutional Animal Care and Use’ committee to ensure conformance to the act ${ }^{2,32,44}$. Adherence to the legislation and guidelines results in a significant financial burden which makes testing unfeasible for many organisations.

Further issues arise from the general public who take particular exception to animal testing; animal rights groups heavily scrutinise experimental testing and have succeeded in encouraging many institutions to have formal policies to eliminate animal testing ${ }^{2,32}$.

When considering animal surrogates as an appropriate sports impact surrogate, one of the key considerations is that the exterior geometries are unrepresentative of human structures and typically provide a poor approximation of inertial parameters. Notable exceptions, such as primates, that are anatomically similar to humans have severe ethical restrictions limiting their use.

It can be assumed to a limited degree of accuracy that humans are biologically similar to other mammals and as such behave in a similar manner on impact. Even so, there are few clinical invasive instrumentation opportunities and as such methods of determining response are difficult to employ. Animals are also inherently impractical as multi-use surrogates due to their biological tissue structures which change in mechanical properties following impact.

The greatest utility of animal surrogates in sports injury evaluation is through the ability to follow the physiological progression of injuries. Using anaesthetised animals it is possible to determine injurious thresholds of tissues under less severe ethical and logistical constraints than other organic surrogates. 


\section{B. Artificial Surrogates}

\section{Synthetic Human Surrogates}

Anthropomorphic Test Devices (ATDs) are artificial test surrogates which aim to approximate human response characteristics on impact ${ }^{61,71}$. They present a feasible alternative to organic surrogates which inherently have many ethical and logistical limitations and offer a means of studying human impact response without physically harming a participant (or animal) ${ }^{12}$.

Physical human tissue structures are orders of magnitude more complex than anything that can be currently manufactured, and the implication is that a synthetic surrogate cannot be used to accurately replicate injuries to soft tissues including muscular, nervous and vascular systems. However, ATDs do present a means of providing controlled, repeatable testing of PPE and injury phenomena as the geometric and material parameters of synthetic tissue can be fixed within pre-established limits which eliminate issues associated with inter-individual differences in size, bone strength, and density present between organic surrogates ${ }^{36,43}$.

Current ATDs have absolute constraints with respect to the size, shape and inertial properties which must be embodied to provide an acceptable approximation of a living human. The main design goal required from synthetic surrogates is repeatability; the ability of the surrogate to reproduce comparable results for each test with the same loading conditions is important to ensure that the surrogate provides a standardised response and means of comparison between trials. Sensitivity is also a key goal; this refers to the ability of the surrogate to produce different results if the specific injury producing stimulus is changed ${ }^{36}$.

The major challenges associated with biofidelic synthetic modelling inherently concern the complexity of the human body. Human tissue materials characterisation is a key issue, as 
human tissues are inhomogeneous and have strain rate dependant properties. Determining an appropriate human tissue material simulant is inevitably a costly endeavour particularly in the early stages of development requiring low volume production runs and one-off tooling costs. An important aspect of any synthetic surrogate is that it exhibits biofidelity. Currently, ATDs must be validated against organic surrogates particularly PMHS to determine their biofidelity $^{32}$. Force-time curves and deflection-time curves are commonly taken from PMHS and recorded and averaged from different specimens. At each instant the mean \pm 1 standard deviation is considered as the human response corridor. It is important that the ATDs mimic PMHS responses in order to accurately predict injury criteria and the likelihood of occurrence; parameters such as acceleration and impulse are generally correlated with injury and trauma $^{37,61}$.

One of the key disadvantages associated with the use of ATDs is the lack of accuracy and detail of representative tissues due to the oversimplification of mechanical tissue substitutes. The human tissue simulant typically does not exactly mimic human structures and will respond to stress consistently and repeatedly instead of biologically (i.e. non-uniformly and inconsistently) like living organisms ${ }^{72}$. In addition, current surrogates do not allow for physiological assessment, including certain aspects of nerve and vascular damage, which are important for determining human impact response and injury severity ${ }^{37}$. Furthermore synthetic surrogates have been generally shown to be a poor representation of human structures when subject to high strain rate impacts ${ }^{13}$. 
It is suggested that there are four critical elements integral to facilitating the development of synthetic surrogates:
a) Size, shape and structure
b) Material property determination and simulant approximation
c) Manufacturing techniques
d) Instrumentation and evaluation

In general, ATDs can be divided into two groups: mechanical and frangible surrogates. For both surrogate types, each of the elements has been individually evaluated relative to the existing state of the art in the field.

\subsection{Mechanical Surrogates}

Mechanical surrogates are multi-use testing devices that give repeatable mechanical responses and can measure physical parameters, such as force and acceleration that can ultimately be linked to injury predictions ${ }^{61}$. They aim to exhibit internal biofidelity in the form of comparable deformations, accelerations and articulations, as well as external biofidelity in similar interactions with the surrounding environment ${ }^{2}$.

Mechanical surrogates are most commonly used within the automotive industry where they have traditionally been used to evaluate restraint system performance ${ }^{32,73}$. There are many ATDs that have been developed for the industry including but not limited to: Euro Side Impact Dummy (EuroSID) ${ }^{74}$, World Side Impact Dummy (WorldSID) ${ }^{75}$, and Test device for Human Occupant Restraint (THOR) ${ }^{76}$ surrogates, however the Hybrid III $^{77}$ series (Fig. 3) are the most widely used mechanical ATDs and as such act as an industry standard ${ }^{71,77}$.

Many researchers also develop bespoke synthetic surrogates for specific research domains. The surrogates are typically highly specialised and reflect the focussed needs of their field. An example of this is a bespoke thigh surrogate developed by Hrysomallis ${ }^{33}$ for cricket thigh 
guards. Data was recorded from drop tests on human volunteers and PMHS thigh segments to determine human injury response limits. This data was then used to validate a physical mechanical surrogate, which was used to determine the protection afforded by thigh guards when impacted by a drop tester.

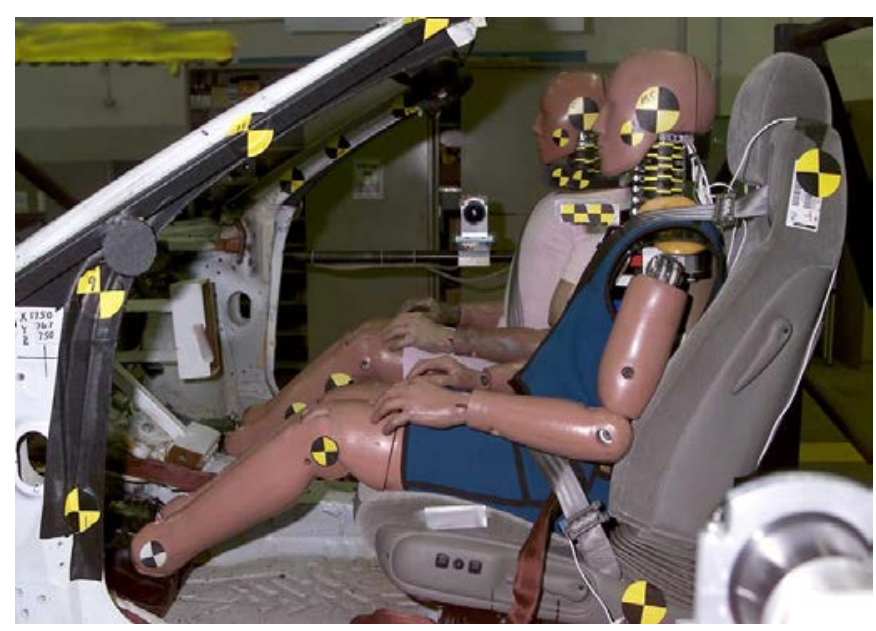

Figure 3 - Hybrid III 50th Percentile Frontal Impact Dummy ${ }^{78}$

a) Size, shape and structure

Two critical characteristics are widely considered to be essential in the development of mechanical surrogates, mass and size, with which basic human impact response can be determined; additionally mechanical surrogates aim to embody the articulations, inertial properties and structural response of living human structures ${ }^{13,37,79}$.

Manufacturers of surrogates have typically considered the $50^{\text {th }}$ percentile US male anthropometric data as a standardised dataset for the development of their models ${ }^{76,77,80}$. The values for a selection of human body segments have been recorded from anthropometric datasets. The $50^{\text {th }}$ percentile US male values have been stated as absolute whilst values for other demographic groups have been given as a percentage difference relative to this reference dataset to the potential error in using the US $50^{\text {th }}$ percentile male surrogates to represent alternate demographic groups. The UK and Chinese populations were selected as representative populations of sporting goods consumers for Europe and Asia respectively. 
Table 3 - Anthropometric data displaying a subset of human body measurements for different demographic groups relative to the $50^{\text {th }}$ percentile US male dataset.

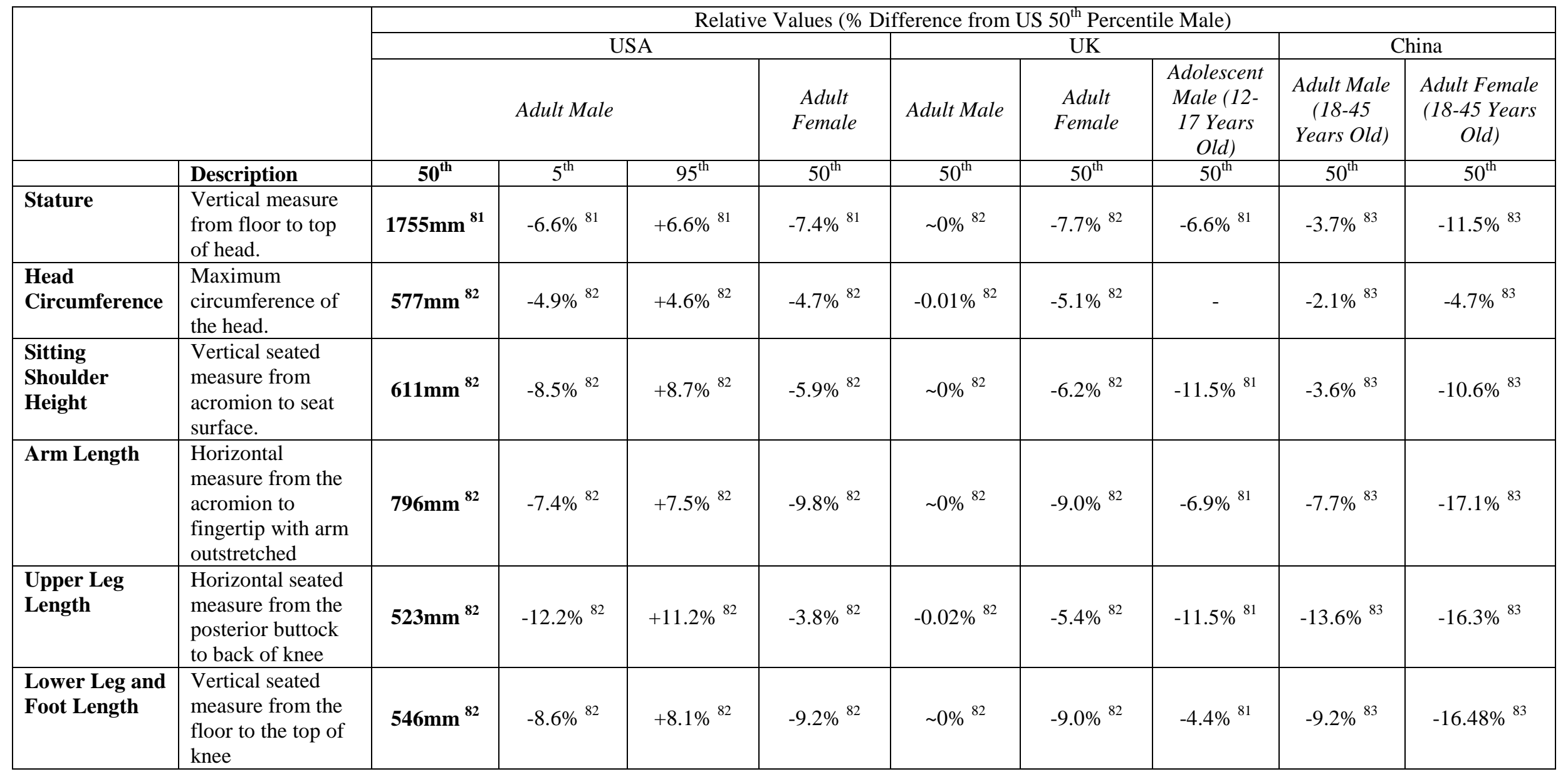


Based on an acceptable error threshold of 5\%, surrogate body segments for different demographic groups that could be based on a $50^{\text {th }}$ percentile US male surrogate include:

- UK adult $50^{\text {th }}$ percentile male - all segments

- Head circumference - all surrogates

- UK adolescent male - lower leg and foot length

Whilst it can be assumed that body segments with a percentage error of greater than $10 \%$ can be considered to be significantly different from the $50^{\text {th }}$ percentile US male dataset, this includes:

- Chinese $50^{\text {th }}$ percentile female - all segments (excl. head)

- UK adolescent male - sitting shoulder height

- Upper leg length - Chinese $50^{\text {th }}$ percentile male, UK adolescent male, US $50^{\text {th }}$ and $95^{\text {th }}$ percentile males.

Where there is a significant difference, the US $50^{\text {th }}$ percentile male surrogate inadequately represents real humans in regards to several important phenomena. When applying a surrogate with these dimensions to other demographic groups one of the major problems may be associated with the local surface interactions of the PPE relative to the human. The outer surface geometries of the human tissue will be different between demographic groups and as such the PPE may not be proximal to the skin in all regions. Similar issues may be apparent with the alignment of the PPE, if the outer surfaces are not representative with the target human tissue, the PPE will move especially when the user is performing movements and when it is impacted. This may be a particular issue if the PPE has specific high protection zones, for example, the field hockey goalkeeper chest protector has a heart zone where additional padding is present to reinforce against sudden blunt force trauma injuries such as commotio cordis, if the PPE moves significantly this may potentially expose vulnerable regions. 
It is suggested that a greater range of sizes are required to better represent the demographic groups that use surrogates to determine injury phenomena and PPE performance. The Chinese female limb segments vary significantly from the US $50^{\text {th }}$ percentile male; this would suggest that it would be necessary to develop surrogates specifically to represent this demographic group. There are some instances in which different demographic groups have body segments with comparable dimensions where a single surrogate would provide a suitable approximation of all of the respective groups. For example, a small upper leg surrogate may well be acceptable for the Chinese adult male, UK adolescent male and $5^{\text {th }}$ percentile US male.

The information presented is limited and is intended to outline some of the potential issues that may be present with generalising a dataset of this type. The measurements given do not present all of the relevant detail necessary to make decisions, for example, using the sitting shoulder height parameter it could be assumed that a $50^{\text {th }}$ percentile US male torso surrogate would be acceptable for both UK and US adult female demographic groups, however the data does not show chest circumference values or shape which can be expected to differ greatly between male and female populations.

Considering the inertial properties of humans, Table 4 provides a subset of information on the inertial characteristics of a human based on information taken from an appropriately sized cadaver approximately representative of a $50^{\text {th }}$ percentile US male. Similar to the anthropometric data, it should not be assumed that these inertial parameters can be accurately extrapolated beyond this population to represent other demographic groups. 
Table 4 - A Subset of Human Body Segmental Inertia Properties [Winter (1990) adapted from Dempster (1955) ${ }^{24}$

\begin{tabular}{|c|c|c|c|c|c|c|c|}
\hline \multirow{2}{*}{ Segment } & \multirow{2}{*}{ Definition } & \multirow{2}{*}{$\begin{array}{c}\text { Segment Mass } \\
\text { (\% of Total } \\
\text { Mass) } \\
\end{array}$} & \multicolumn{2}{|c|}{ Centre of Mass (\% of Segment Length) } & \multicolumn{3}{|c|}{ Radius of Gyration (\% of Segment Length) } \\
\hline & & & Proximal & Distal & Centre of Mass & Proximal & Distal \\
\hline Head \& Neck & $\begin{array}{l}\text { C7 T1 and } 1^{\text {st }} \text { rib/ear } \\
\text { canal }\end{array}$ & 8.1 & 100 & - & 49.5 & 112.0 & - \\
\hline $\begin{array}{l}\text { Thorax \& } \\
\text { Abdomen }\end{array}$ & C7 T1/ L4-L5 vertebra & 35.5 & 63.0 & 37.0 & - & - & - \\
\hline Total Arm & $\begin{array}{l}\text { Glenohumeral } \\
\text { joint/ulnar styloid }\end{array}$ & 5.0 & 53.0 & 47.0 & 36.8 & 64.5 & 59.6 \\
\hline Thigh & $\begin{array}{l}\text { Greater } \\
\text { trochanter/femoral } \\
\text { condyles }\end{array}$ & 10.0 & 43.3 & 56.7 & 32.3 & 54.0 & 65.3 \\
\hline Foot \& Leg & $\begin{array}{l}\text { Femoral } \\
\text { condyles/medial } \\
\text { malleolus }\end{array}$ & 6.1 & 60.6 & 39.4 & 41.6 & 73.5 & 57.2 \\
\hline
\end{tabular}

Table 5 - Percentage Differences in Masses of Demographic Groups from $50^{\text {th }}$ Percentile US Male Measurements

\begin{tabular}{|c|c|c|c|c|c|c|c|c|c|}
\hline & \multicolumn{9}{|c|}{ Relative Values (\% Difference from US $50^{\text {th }}$ Percentile Male) } \\
\hline & \multicolumn{4}{|c|}{ USA } & \multicolumn{3}{|c|}{ UK } & \multicolumn{2}{|c|}{ China } \\
\hline & \multicolumn{3}{|c|}{ Adult Male } & \multirow{2}{*}{$\begin{array}{c}\text { Adult Female } \\
\qquad 50^{\text {th }}\end{array}$} & \multirow{2}{*}{$\begin{array}{c}\text { Adult Male } \\
\qquad 50^{\text {th }}\end{array}$} & \multirow{2}{*}{$\begin{array}{c}\text { Adult Female } \\
50^{\text {th }}\end{array}$} & \multirow{2}{*}{$\begin{array}{c}\text { Adolescent Male } \\
(12-17 \text { Years Old })\end{array}$} & \multirow{2}{*}{$\begin{array}{c}\text { Adult Male } \\
\text { (18-45 Years } \\
\text { Old) } \\
50^{\text {th }}\end{array}$} & \multirow{2}{*}{$\begin{array}{c}\text { Adult Female } \\
\text { (18-45 Years } \\
\text { Old) } \\
50^{\text {th }}\end{array}$} \\
\hline & $\mathbf{5 0}^{\text {th }}$ & $5^{\text {th }}$ & $95^{\text {th }}$ & & & & & & \\
\hline Mass (kg) & $82.1^{82}$ & $-33.9 \%{ }^{82}$ & $+34.0 \%{ }^{82}$ & $-15.5 \%^{82}$ & $-2.80 \%^{82}$ & $-18.8 \%^{82}$ & $-34.6 \%{ }^{81}$ & $-28.1 \%^{83}$ & $-36.7 \%^{83}$ \\
\hline
\end{tabular}


Based on the available data (Table 5), using the inertial parameters of a US $50^{\text {th }}$ percentile male instead of a demographic specific dataset results in estimated inertial errors of up to $36.7 \%$ where the motion is solely translational. In sports impact scenarios, however, rotation occurs as a resultant motion and the moment of inertia is a relevant consideration, this has been estimated based on the differences in total mass and body segment dimension error (Eq.1).

$I=m_{i} l^{2}$

$I=$ Moment of Inertia $\left(\mathrm{kg} \cdot \mathrm{m}^{2}\right)$

$m_{i}=$ percentage error of total body mass

$l=$ percentage error in length of limb segment

Table 6 - Percentage Differences in Moment of Inertia from 50th Percentile US Male Parameters

\begin{tabular}{|l|c|c|c|c|c|c|c|c|}
\hline \multirow{2}{*}{} & \multicolumn{3}{|c|}{ USA } & \multicolumn{2}{c|}{ UK } & \multicolumn{2}{c|}{ China } \\
\cline { 2 - 9 } & \multicolumn{2}{|c|}{ Adult Male } & $\begin{array}{c}\text { Adult } \\
\text { Female }\end{array}$ & $\begin{array}{c}\text { Adult } \\
\text { Male }\end{array}$ & $\begin{array}{c}\text { Adult } \\
\text { Female }\end{array}$ & $\begin{array}{c}\text { Adolescent } \\
\text { Male }(12- \\
17 \text { Years } \\
\text { Old })\end{array}$ & $\begin{array}{c}\text { Adult } \\
\text { Male } \\
(18-45 \\
\text { Years } \\
\text { Old }\end{array}$ & $\begin{array}{c}\text { Adult } \\
\text { Female } \\
(18-45 \\
\text { Years } \\
\text { Old) }\end{array}$ \\
\cline { 2 - 9 } & $5^{\text {th }}$ & $95^{\text {th }}$ & $50^{\text {th }}$ & $50^{\text {th }}$ & $50^{\text {th }}$ & $50^{\text {th }}$ & $50^{\text {th }}$ & $50^{\text {th }}$ \\
\hline Head \& Neck & $-40.2 \%$ & $46.6 \%$ & $-23.3 \%$ & $-2.8 \%$ & $-26.9 \%$ & - & $-31.1 \%$ & $-42.5 \%$ \\
\hline Thorax \& Abdomen & $-44.7 \%$ & $58.3 \%$ & $-25.2 \%$ & $-2.8 \%$ & $-28.6 \%$ & $-48.8 \%$ & $-33.2 \%$ & $-49.4 \%$ \\
\hline Total Arm & $-43.3 \%$ & $54.9 \%$ & $-31.3 \%$ & $-2.8 \%$ & $-32.8 \%$ & $-43.3 \%$ & $-38.7 \%$ & $-56.5 \%$ \\
\hline Thigh & $-49.0 \%$ & $65.7 \%$ & $-21.8 \%$ & $-2.8 \%$ & $-27.3 \%$ & $-48.8 \%$ & $-46.3 \%$ & $-55.7 \%$ \\
\hline Foot \& Leg & $-44.8 \%$ & $56.6 \%$ & $-30.3 \%$ & $-2.8 \%$ & $-32.8 \%$ & $-40.2 \%$ & $-40.7 \%$ & $-55.8 \%$ \\
\hline
\end{tabular}

The data presented in Table 6 shows significant percentage errors in the moment of inertia for most demographic groups, with many segments varying by more than $40 \%$. The Chinese female and $95^{\text {th }}$ percentile US male showed the most significant deviations from the $50^{\text {th }}$ percentile US male dataset, with the $95^{\text {th }}$ percentile US male thigh segment differing by the greatest margin (65.7\%) from the $50^{\text {th }}$ percentile US male surrogate. Many elite athletic populations will be larger than the $50^{\text {th }}$ percentile dataset and potentially closer to the $95^{\text {th }}$ percentile demographic, particularly in sports such as American Football or Rugby. When using a $50^{\text {th }}$ percentile US male surrogate to represent a far broader population, the errors in 
the segmental inertia properties will significantly affect the response of the surrogate on impact.

The differences in tissue compositions between individuals also have the potential to affect the inertial properties. Most athletic demographic groups are likely to have higher proportions of muscle compared to subcutaneous fat tissue, and a greater bone density. These differences are not specifically reflected by the standard inertial properties data, therefore attempting to use these parameters beyond the population from which the initial measurements were taken incurs in its own associated inaccuracies.

Using well defined standardised body dimensions provides an accurate means of comparison with PMHS data and other synthetic surrogates ${ }^{59}$. However, the use of a well-established dataset has its disadvantages: the anthropometric profiles of humans have changed over the past few decades and the previous assumptions made are almost not as representative of the current user population as they once were. THOR was developed as a more biofidelic alternative to the Hybrid III, and was consequently constructed from more recent biomechanical data, which also provided a more accurate range of motion and joint torque characteristics, a notable shortcoming of the Hybrid III dummy ${ }^{76,84}$.

Sophisticated mechanical surrogates, such as the UK Transport Research Laboratories (TRL) pedestrian legform ${ }^{85}$ have moulded the outer geometries of a volunteer human leg with representative anthropometric data using moulding agents such as Alginate to provide a more accurate description of the human external tissue geometries.

Most mechanical surrogates embody simplify approximations of human structures through single or dual artificial tissue constructions with representative outer surface geometries. One of the key aims in the development of mechanical surrogates is to match the inertial properties of the segment through accurate mass distributions within the structures; however 
with limited structural tissue complexities only restricted tissue level response data can be obtained.

Internal human structures are typically approximated with simplified geometries. For instance, the bone segments of the surrogate are commonly cylindrical tubes or bars, which approximate the rough dimensions of the given human structure (e.g. the TRL legform which uses straight cylindrical bones using data taken from average cross-sectional values of human bone).

\section{b) Material Property Determination and Simulant Approximation}

Typically, in most mechanical surrogates the requirements for repeatability exceed those for biofidelity and hence mechanical surrogates are constructed from very robust, durable materials that can be impacted many times under extreme loading conditions without affecting their response characteristics ${ }^{2}$. Particular attention is generally given to the stiffness and soft tissue simulant damping properties which have an impact on the load transfer. Artificially high mechanical tissue simulant strengths are often desirable to ensure premature failure does not occur ${ }^{13,37}$. There also needs to be a high level of reproducibility between surrogates whereby each surrogate must behave in the same manner as the previous one to ensure consistency between trials.

For example, in the Hybrid III dummy durability and repeatability requirements exceed biofidelity. Owen et al. ${ }^{86}$ found that for non-injurious testing the Hybrid III peak axial force experienced at the tibia was approximately 1.2-1.6 times higher than measured on a PMHS. They suggest this is due to the modulus of elasticity of bone increasing with strain rate raised to the power 0.06 , hence the velocity of impact influences the force experienced, which is not the case for the Hybrid III's metal shaft skeletal components ${ }^{61}$. 


\section{c) Manufacturing Techniques}

Mechanical ATD’s are generally constructed using a steel skeleton, surrounded by synthetic rubber materials to simulate soft tissue. Typically manufacturing methods for mechanical surrogates involve the use of a steel or aluminium pipe or bar with appropriate cross section and injection moulding a rubber composite around the bone. The Hybrid III ATDs utilise an instrumented tibia called the Denton $\mathrm{Leg}^{87}$, which consists of a simple metallic shaft that articulates at the knee with a pin joint and at the ankle with a ball and socket joint.

More sophisticated mechanical surrogates (e.g. the TRL legform or the Flexible Pedestrian Legform Impactor, FLEX PLI ${ }^{88}$ ) may include additional tissue structures to increase biofidelity of the surrogates. The TRL legform skeletal surrogate tissue is an epoxy filled glass fibre cylinder, as this material was found to exhibit properties similar to static mechanical property values for the strength and stiffness of human bones, demonstrating little deflection and creep before fracture occurs. An energy absorbing polyurethane foam material was selected as the soft tissue simulant as it had a hardness value of approximately 15A on the Shore 'A' scale, which was shown to be of comparable hardness to tensed human tissue $^{85,89}$. An outer skin layer was considered with a 3mm thick neoprene layer which approximates an average thickness for human skin, which ranges in thickness from 0.5-4mm.

The TRL legform has been subject to criticism, as have most mechanical surrogates, in that the standard engineering materials used cannot provide an accurate representation of the viscoelastic properties of the human body. The neoprene skin and polyurethane foam have both been criticised for their low biofidelity. Lawrence \& Hardy ${ }^{90}$ suggest that the TRL legform does not have a biofidelic mass distribution either due to its construction from steel bones and soft tissue flesh ${ }^{89}$. 
Most mechanical surrogates use simple mechanical joints such as pin joints or hinge joints, to provide a single degree of freedom movement about the joint centre. Some mechanical surrogates opt for more complicated joint designs, whereby the ligaments are modelled to provide additional accuracy. The TRL legform used straight metal ligaments at the knee joint, whilst the FLEX PLI used a multi-segmented body approach with cabled ligament representations to provide a better representation of knee flexion when impacted by a vehicle $^{88,91,92}$.

\section{d) Instrumentation and Evaluation}

Instrumentation is required to measure kinetic and kinematic parameters associated with the injury event to quantitatively characterise the phenomena occurring. Previous researchers have prioritised measures such as accelerations, forces, moments and displacements. Mechanical surrogates generally include instrumentation in the form of load cells, strain gauges, accelerometers and displacement transducers. High speed video is often employed separately to determine displacements ${ }^{37,43}$. Many sensors are required to provide full characterisation of the interactions occurring at the surrogate during the impact event, Been et al. ${ }^{93}$ suggest that whole-body-response requires head-to-toe transducers with more than 135 channels of instrumentation; therefore the limb segments are generally isolated for testing to reduce expense and time spent through redundant data capture and the risk of damage or unnecessary recalibrations of sensors. It is suggested that the commercial cost of a Hybrid III ATD is approximately $\$ 35,000$ and this cost is more than tripled when the dummy is fully instrumented.

Mechanical surrogates do not visually exhibit any physical signs of injury in response to the same loads that would cause visible injury to humans and hence the information obtained from instrumentation must be correlated with injury data from organic surrogate studies in 
order to determine a risk of injury; this is usually expressed as a probability curve rather than a definitive threshold as the likelihood of injury is dependent on gender, physical condition and other predisposing factors (e.g. previous injuries) ${ }^{2,94}$.

The THOR lower leg contains load cell's in the upper and lower regions of the tibia as well as mid-tibia and mid-foot accelerometers, and an ankle angle potentiometer ${ }^{61}$. However the features which increase the biofidelity of the THOR surrogate in relation to the Hybrid III also make the ATD more expensive and potentially more vulnerable to failure ${ }^{13}$.

When considering the applicability of mechanical synthetic surrogates as tools for sports injury evaluation, one of their key advantages is in the ease of usage without ethical or logistical issues associated with obtaining specimens as is present in organic surrogates. As the surrogates are manufactured from standard engineering materials there is invariably a high level of control and reproducibility over the responses of the simulated human tissues, which is desirable for sports impact surrogates in providing a consistent standardised medium for testing.

Through effective geometry acquisition and moulding techniques they have the capacity to provide a representative degree of exterior geometric accuracy for the interfacing surfaces in the impact event. Whilst it is accepted that organic surrogates provide a more accurate representation of tissue structures, a good approximation can be achieved with a considered choice of human tissue simulant materials and manufacturing techniques.

Another key advantage of using mechanical surrogates lie in the degree of instrumentation that can be embedded without significantly compromising the gross biofidelity of the surrogate, which cannot be attained effectively using organic surrogates. 
A greater consideration is afforded to the durability and repeatability characteristics of mechanical surrogates, which make them useful for repeat impact testing, however the biofidelity of individual tissue responses is consequently compromised (e.g. bone fracture thresholds are artificially increased). The greatest utility of mechanical surrogates in sports injury evaluation is through repeat impact testing protocols using a physical medium which can be impacted consistently several times before failure. This is particularly valuable in fatigue testing of PPE and in general standardisation studies where a consistent physical surrogate is required.

\subsection{Frangible Surrogates}

Frangible surrogates are defined as test structures that are designed to sustain permanent damage in a manner similar to a human body ${ }^{61}$. This makes the surrogates single use and consequently more expensive per test than mechanical alternatives ${ }^{37,43,54}$.

Frangible surrogates represent a somewhat undeveloped research domain and thus relatively few have been developed. They have most commonly been used in the military, with specific consideration to AP land mine testing. Several axial loading surrogates have been developed such as the Red Deer Lower Leg ${ }^{95}$, Simplified Lower Leg ${ }^{96}$ and Complex Lower Leg ${ }^{97}$. The Frangible Surrogate Leg (FSL) ${ }^{80}$, in particular represents one of the most complex and sophisticated frangible surrogates developed.

a) Size, shape and structure

Frangible ATD’s have employed a greater diversity of tissue structures than mechanical surrogates. The surrogates are more concerned with specific failure modes for single-use injury evaluation; therefore more closely matched human material properties are necessary to provide an indication for accurate post mortem evaluation. 
The shape complexities exhibited in frangible surrogates are typically more refined than in mechanical surrogates, with internal structures more intricately considered. Although the $50^{\text {th }}$ percentile anthropometries are still often used as a standard measure and means of comparison, anthropometric data is often used from volunteer human subjects or anatomical human datasets that closely follow the target demographic groups.

Advances in various imaging techniques (e.g. Magnetic Resonance Imaging (MRI) and Computer Tomography (CT)) present the ability to accurately capture the shape of anatomical structures. However, use of these techniques is currently expensive and this restricts widespread use to enlarge the range of demographic groups represented by available surrogates. Nevertheless, sophisticated surrogates such as the FSL have used a combination of CT scans of humans and moulds of exterior human tissue profiles to provide the geometric data for the surrogate.

\section{b) Material Property Determination and Simulant Approximation}

Frangible surrogates are the design solution when tissue failure biofidelity is the main design goal. There is, however, a requirement for high levels of consistency between individual surrogates so that comparisons can be legitimately made.

Material property data is generally determined from sources of published literature. However, there is currently insufficient data to accurately characterise human tissue properties, especially under dynamic and high strain rate conditions; much of the data available is from PMHS or animal surrogates where substantial assumptions are required to draw parallels with human behaviour.

A meta-analysis has been conducted of the mechanical properties from five major tissue structures in the human body. Three properties have been extracted to best describe the 
overall structure and behaviour of the tissues: density, Young's modulus and ultimate tensile strength.

Table 7 - Density Values of Human Tissues

\begin{tabular}{|c|c|c|c|}
\hline & Source & Description & Density $\left(\mathrm{kg} / \mathrm{m}^{3}\right)$ \\
\hline \multirow[t]{2}{*}{ Cortical Bone } & $\begin{array}{l}\text { Yeni et al. } \\
(1998)^{98}\end{array}$ & $\begin{array}{l}\text { In vitro measurements of human femur } \\
\text { specimens }\end{array}$ & $1.88 \pm 0.05 \times 10^{3}$ \\
\hline & $\begin{array}{l}\text { Bensamoun et al. } \\
(2004)^{99}\end{array}$ & $\begin{array}{l}\text { In vivo testing of human femur bone } \\
\text { using ultrasonic techniques }\end{array}$ & $1.49-2.13 \times 10^{3}$ \\
\hline \multirow[t]{2}{*}{ Trabecular Bone } & $\begin{array}{l}\text { Carter \& Hayes } \\
(1976)^{100}\end{array}$ & $\begin{array}{l}\text { In vitro testing of human and bovine } \\
\text { proximal tibia tissue }\end{array}$ & $0.07-0.97 \times 10^{3}$ \\
\hline & $\begin{array}{l}\text { Lotz et al. } \\
(1990)^{101}\end{array}$ & $\begin{array}{l}\text { In vitro testing of fresh specimens of the } \\
\text { human femoral neck. }\end{array}$ & $0.18-0.95 \times 10^{3}$ \\
\hline \multirow[t]{2}{*}{ Muscle } & $\begin{array}{l}\text { Ward \& Lieber } \\
(2005)^{102}\end{array}$ & $\begin{array}{l}\text { In vitro tissues, } 37 \% \text { formaldehyde-fixed } \\
\text { (vastus lateralis, psoas major, tibialis } \\
\text { anterior) }\end{array}$ & $1.06 \times 10^{3}$ \\
\hline & $\begin{array}{l}\text { Keys \& Mendes } \\
(1960)^{103}\end{array}$ & 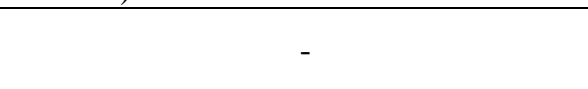 & $1.11 \times 10^{3}$ \\
\hline \multirow[t]{2}{*}{$\begin{array}{l}\text { Subcutaneous } \\
\text { Adipose Tissue }\end{array}$} & $\begin{array}{l}\text { Fidanza et al. } \\
(1954)^{104}\end{array}$ & $\begin{array}{l}\text { In vitro testing of human tissues taken } \\
\text { directly from surgery }\end{array}$ & $0.92 \times 10^{3}$ \\
\hline & Farvid (2005) ${ }^{105}$ & $\begin{array}{l}\text { In vivo testing of human tissues using } \\
\text { bioelectrical impedance techniques. }\end{array}$ & $0.92 \times 10^{3}$ \\
\hline Skin & $\begin{array}{l}\text { Sarvazyan et al. } \\
(1998)^{106}\end{array}$ & $\begin{array}{l}\text { In vitro testing of human tissue using } \\
\text { shear wave elasticity imaging }\end{array}$ & $1.10 \times 10^{3}$ \\
\hline
\end{tabular}

Table 8 - Ultimate Tensile Strength Values of Human Tissues

\begin{tabular}{|l|l|l|l|}
\hline & Source & Description & $\begin{array}{l}\text { Ultimate Tensile } \\
\text { Strength (MPa) }\end{array}$ \\
\hline Cortical Bone & $\begin{array}{l}\text { Burstein et al. } \\
(1976)^{107}\end{array}$ & $\begin{array}{l}\text { In vitro tensile tests on human tibia and } \\
\text { femur samples, from PMHS aged 20-29. }\end{array}$ & 140 \\
\cline { 2 - 4 } & $\begin{array}{l}\text { Yamada (1970) } \\
108\end{array}$ & $\begin{array}{l}\text { In vitro quasi-static tensile tests on fresh } \\
\text { unembalmed human femur specimens } \\
\text { from PMHS aged 20-39 }\end{array}$ & $124 \pm 1$ \\
\hline Trabecular Bone & $\begin{array}{l}\text { Rohlmann et al. } \\
(1980)^{109}\end{array}$ & $\begin{array}{l}\text { In vitro tensile tests on the human } \\
\text { proximal femur }\end{array}$ & $6.8 \pm 4.8$ \\
\cline { 2 - 4 } & $\begin{array}{l}\text { Keaveny et al. } \\
(1994)^{110}\end{array}$ & $\begin{array}{l}\text { In vitro tensile tests on human proximal } \\
\text { tibia }\end{array}$ & $24 \pm 8.3$ \\
\hline Muscle & $\begin{array}{l}\text { Yamada (1970) } \\
108\end{array}$ & $\begin{array}{l}\text { In vitro tensile tests on human rectus } \\
\text { abdominus muscle specimens from } \\
\text { PMHS aged 20-39 }\end{array}$ & $1.07 \times 10^{-4}$ \\
\cline { 2 - 5 } & $\begin{array}{l}\text { Friden \& Lieber } \\
(1970)^{111}\end{array}$ & $\begin{array}{l}\text { In vitro tensile tests on human upper } \\
\text { extremity muscle specimens }\end{array}$ & $9 \times 10^{-3}$ \\
\hline & Vogel (1987) $^{112}$ & $\begin{array}{l}\text { In vitro tensile tests on excised human } \\
\text { skin from the sternum }\end{array}$ & $5-32$ \\
\cline { 2 - 4 } & $\begin{array}{l}\text { Jacquemond et al. } \\
(2007)^{113}\end{array}$ & $\begin{array}{l}\text { In vitro tensile tests on excised forehead } \\
\text { and arm skin from a 85 year old PMHS }\end{array}$ & $19.5-87.1$ \\
\cline { 2 - 4 } & $\begin{array}{l}\text { Diridollou et al. } \\
(2000)^{114}\end{array}$ & $\begin{array}{l}\text { In vivo testing of human skin using } \\
\text { ultrasound and suction techniques }\end{array}$ & $13.5 \pm 5 \times 10^{-3}$ \\
\hline
\end{tabular}


Table 9 - Young's Modulus Values of Human Tissues

\begin{tabular}{|c|c|c|c|}
\hline & Source & Description & $\begin{array}{l}\text { Young's Modulus } \\
\text { (GPa) }\end{array}$ \\
\hline \multirow[t]{2}{*}{ Cortical Bone } & $\begin{array}{l}\text { Burstein et al. } \\
(1976){ }^{107}\end{array}$ & $\begin{array}{l}\text { In vitro testing of the human femur and } \\
\text { tibia specimens. }\end{array}$ & $\begin{array}{l}17 \pm 2.2 \text { (tension); } \\
18.1 \pm 0.3 \text { (compression) }\end{array}$ \\
\hline & $\begin{array}{l}\text { Yamada }(1970) \\
108\end{array}$ & $\begin{array}{l}\text { In vitro quasi-static tensile tests on fresh } \\
\text { unembalmed human humerus specimens } \\
\text { from PMHS aged 20-39 }\end{array}$ & 17.2 \\
\hline \multirow[t]{2}{*}{ Trabecular Bone } & $\begin{array}{l}\text { Carter \& Hayes } \\
(1977){ }^{115}\end{array}$ & $\begin{array}{l}\text { In vitro testing of the human proximal } \\
\text { tibia in uniaxial compression }\end{array}$ & $10-500 \times 10^{-3}$ \\
\hline & $\begin{array}{l}\text { Ciarelli et al. } \\
(1986)^{116}\end{array}$ & $\begin{array}{l}\text { In vitro compressive testing of specimens } \\
\text { of human proximal femur. }\end{array}$ & $49-572 \times 10^{-3}$ \\
\hline \multirow[t]{2}{*}{ Muscle } & $\begin{array}{l}\text { Zil’bergleit et al. } \\
\text { (1982) }\end{array}$ & $\begin{array}{l}\text { In vitro cyclic tensile loading of the } \\
\text { human biceps brachii }\end{array}$ & $0.4 \pm 0.1 \times 10^{-5}$ \\
\hline & $\begin{array}{l}\text { Friden \& Lieber } \\
\text { (2003) }\end{array}$ & $\begin{array}{l}\text { In vitro tensile tests on human upper } \\
\text { extremity muscle specimens }\end{array}$ & $28 \pm 3 \times 10^{-6}$ \\
\hline \multirow[t]{3}{*}{$\begin{array}{l}\text { Subcutaneous } \\
\text { Adipose Tissue }\end{array}$} & $\begin{array}{l}\text { Van Houten et al. } \\
(2003){ }^{118}\end{array}$ & $\begin{array}{l}\text { In vivo magnetic resonance elastography } \\
\text { of human breast tissue }\end{array}$ & $20.9 \pm 3.5 \times 10^{-6}$ \\
\hline & $\begin{array}{l}\text { Erdemir et al. } \\
(2007){ }^{119}\end{array}$ & $\begin{array}{l}\text { In vivo indentation and ultrasound of the } \\
\text { human heel pad }\end{array}$ & $49.4 \times 10^{-6}$ \\
\hline & $\begin{array}{l}\text { Samani \& Plewes } \\
(2004){ }^{120}\end{array}$ & $\begin{array}{l}\text { In vitro indentation tests on specimens of } \\
\text { human breast tissue }\end{array}$ & $3.6 \times 10^{-3}$ \\
\hline \multirow[t]{3}{*}{ Skin } & $\begin{array}{l}\text { Geerligs et al. } \\
(2011)^{121}\end{array}$ & $\begin{array}{l}\text { In vivo micro indentation testing of } \\
\text { human epidermis }\end{array}$ & $2.16 \times 10^{-3}$ \\
\hline & $\begin{array}{l}\text { Delalleau et al. } \\
(2008)^{122}\end{array}$ & $\begin{array}{l}\text { In vivo suction testing of human forearm } \\
\text { skin }\end{array}$ & $5.67 \times 10^{-6}$ \\
\hline & $\begin{array}{l}\text { Ni'Annaidh et al. } \\
(2012)^{123}\end{array}$ & $\begin{array}{l}\text { In vitro tensile testing of excised human } \\
\text { skin }\end{array}$ & $83.3 \pm 34.9$ \\
\hline
\end{tabular}

There is an extensive body of literature (Table $7,8,9$ ) that has researched the mechanical properties of human tissues, which has contributed to our understanding of the composition and behaviour of the structural components. There is however a large variance in properties present in reported datasets dependant on their testing sites, conditions and measurement techniques.

Cortical bone tissue can be practically considered to be homogeneous in synthetic models due to the comparable results exhibited between tests, conditions and locations. The other tissues reported greatly inconsistent properties between tests, indicating that they are inhomogeneous, anisotropic, viscoelastic and strain rate dependant. 
The differences apparent between tests conducted in vivo and in vitro are significant which most likely indicates inaccuracies in both approaches. Conducting mechanical testing in vivo relies on non-invasive methodologies such as suction, indentation, and imaging techniques have not been extensively utilised and their accuracy still remains in question. The tests are often skewed by the surrounding tissue making it difficult to isolate the properties of the particular tissue of interest (e.g. indentation techniques to determine the properties of muscular tissue are skewed by the layer of subcutaneous tissue and skin). Whilst in vitro tests are conducted with excised human tissue which can be tested to failure but inherently lacks the structure and tonicity of live tissue.

The testing is also typically conducted under static or quasi-static loading conditions, which do not account for the behaviour of the tissues under differing strain rates. Dynamic impact testing is a particularly pertinent consideration in sports impact scenarios where the human body is impacted under rapidly changing conditions. There have been attempts to characterise the dynamic behaviour of human tissue ${ }^{100,124-133}$, however there are issues with the low levels of accuracy and reproducibility obtained which suggest that there is insufficient dynamic test data to determine the mechanical properties of human tissues at different strain rates.

Synthetic polymers are typically used to model skeletal components with reinforced thermoset resins most often chosen as the preferred biofidelic skeletal simulant. Geometrically accurate skeletal components made using a glass fibre reinforced epoxy exterior moulded around a polyurethane core are commercially available (e.g. Sawbones). The components accurately mimic PMHS performance under static loading conditions ${ }^{134-136}$. Frangible ATD’s commonly use water based gels to approximate muscle tissues. Ballistics gelatin is often used as the preferred soft tissue simulant for military applications as it has served as an international standard for ballistic wound research ${ }^{137,138}$. Consequently the FSL 
used a molten ballistic pigskin gelatin $\left(20 \%\right.$ aq. at $\left.10^{\circ} \mathrm{C}\right)$ as a muscle tissue simulant ${ }^{36}$. A range of companies also specialise in the commercial development of bespoke simulant tissues to tailor to specific medical industry requirements (e.g. Syndaver ${ }^{\mathrm{TM}}$ ). Hydrogels are used as a preferred soft tissue simulant for medical training (hydrophilic polymer molecules that retain a large quantity of water). The chemical formulation can be altered alongside levels of water, fibre and salts to change the mechanical and physical properties relative to the specific demands of the user. The individual bespoke tissue structures are then validated directly against well preserved in vitro human tissue specimens or animals to ensure that they behave in a similar manner.

One of the main issues associated with frangible human tissue simulants, however, is that they often require refrigeration to prolong useful storage life and rely on an expert medical prognosis from post-test autopsies as the use of PMHS does ${ }^{36,37}$.

\section{c) Manufacturing Techniques}

A wide range of manufacturing methods are employed to construct frangible ATDs, largely dependent on the materials used. The skeletal component is typically injection or rotation moulded around a core or insert representing less dense structures in the tissue (e.g. the FSL skeletal components were rotationally spun cast to provide cavities for marrow inserts).

The muscle tissue simulant is generally injection moulded into a 2-part mould with a detailed geometric complexity representing a biofidelic shape and smooth surface finish. Other tissue structures such as ligaments, tendons, and skin, which are modelled in some frangible ATDs, employ varying construction techniques between surrogates. For example, in the FSL, ligaments were modelled using high temperature, high flexibility polyamide glue; tendons were simulated using flat and tubular polymeric material at anatomical positions of the articulating bones of the knee and the ankle joints; whilst a gel soaked nylon stocking, which 
fitted over the leg and melted into the superficial layer of gelatin using a paintbrush and hot water was used to represent the outer skin tissue. However, the FSL skin simulant has been shown to be significantly more fragile than human skin, whilst the soft tissue simulant had a low fidelity response to gas penetration and required specific storage requirements ${ }^{36}$.

The mechanical complexity of human joints is perhaps impossible to duplicate with current manufacturing and materials technology, at least cost effectively. Therefore most frangible surrogates typically use simple mechanical approximations. Very sophisticated surrogates may attempt to simulate the approximate range of motion at the respective joints using different combinations and stiffness's of materials to create a gross global biofidelity about the joint (e.g. the FSL used a high flexibility polyamide glue simulate the support experienced at the knee joint).

\section{d) Instrumentation and Evaluation}

Frangible surrogates are designed to replicate the actual damage mechanisms experienced by living humans under similar loading conditions rather than requiring that researchers infer the likelihood of damage from the observation of causal phenomena. As a result frangible surrogates are evaluated predominantly through autopsy-based procedures to determine mechanical damage. However, a lack of detailed internal structures representative of soft tissues and organs in surrogates is often an issue and consequently measurements of force or acceleration must be utilised to infer rather than observe stresses within a given structure of interest ${ }^{2}$. Therefore a variety of instrumentation such as load cells, pressure transducers, and strain gauges are incorporated and complimented by high-speed imagery. The FSL was instrumented with triple rosettes at the mid-shaft femur and distal 1/3 tibia along with a pair of uniaxial circumferential strain gauges at the proximal and distal tibia. It also contains Knee and heel mounted accelerometers provided information on the ‘crumple zone' action of the 
lower leg ${ }^{43}$. The commercial cost of a single use FSL with instrumentation is approximately $£ 2,500$. Introducing instrumentation commonly reduces the surrogate’s biofidelity though. In the case of the FSL the embedded instrumentation was shown however to create artificial stress risers and lead to premature fractures ${ }^{13}$.

When considering frangible synthetic surrogates as an appropriate sports surrogate it must be noted that similar to durable mechanical surrogates, detailed replication of all tissue structures cannot be achieved cost effectively. However an acceptable level of accuracy can be obtained with regards to specific exterior human geometries and inertial parameters.

Frangible surrogates typically possess a greater diversity of human tissue structures than durable mechanical surrogates and contain an increased tissue simulant biofidelity. Injuries can consequently be assessed at a more detailed tissue level, where specific injury mechanisms can be applied to tissue structures. The increased biofidelity of tissue structures, however, compromises the durability of the surrogates and hence are single use when subject to injurious loads.

Fundamentally frangible surrogates provide to the sports industry a synthetic PMHS, where injurious scenarios can be accurately modelled and actual damage can be visually monitored. Within the sports industry from both a logistical and ethical standpoint it is largely preferable to avoid usage of PMHS and animal surrogates as they are perceived to reflect negatively on the brand. Therefore, a frangible synthetic alternative that provides an accurate description of injury is a far superior alternative.

In sports injury evaluations, the greatest utility of frangible surrogates is through single impact injurious testing of complex structures, which cannot be considered in sufficient detail using durable mechanical surrogates (e.g. high speed projectile impacts to the torso from a hockey ball). 


\section{Computational Models of Human Structures}

The utility of computational models in injury biomechanics research has markedly increased in the past few decades. Since their inception ${ }^{139}$ computational models have become important in facilitating accurate determination of human response in impact scenarios ${ }^{2}$.

Computational models in injury biomechanics research refer to virtual human surrogates, that aim to exhibit a biofidelic impact response when combined with a mathematical description of environmental and impact conditions. The human body consists of a series of intricate anatomical structures with complex geometries, made up of a variety of interacting tissues $^{140,141}$; computational modelling aims to provide an accurate description of the structures, kinematics of joints and the physiological interactions between the tissues ${ }^{7,140}$. They are often used to analyse biomechanical experiments and quantify specific input parameters. One of the key advantages of computational modelling in injury biomechanics research is that different injury mechanisms can be studied without causing harm to the athlete. The virtual nature of the surrogates means that there is no physical material cost associated with each model, once formulated, support the exploration of a wide range of variable perturbations without physical manufacturing costs or delays. Computational models can replace time-consuming and expensive experimental measures and provide a method of predicting internal measurable phenomena such as muscular forces ${ }^{142}$. However the immense complexity of the human body continues to make accurate computational modelling challenging $^{140}$ and the development time associated with even a single body segment representing a single individual is non-trivial. Where a limited set of observable external phenomena are used to validate the accuracy of an increasingly complex set of internal phenomena an increasing level of caution is warranted. 
Computational modelling has a wide range of industrial applications, and is capable of performing a diverse series of operations. The operations required of the models differ from anatomical representation and external surface tissue deformation (e.g. ergonomics, virtual reality, gaming, film industry) to accurate internal and external anatomical and physiological modelling (e.g. biomechanics, medical, automotive, military).

It is widely considered that further development in the field towards more accurate, validated models can reduce the requirement for expensive experimental set ups and provide a more simple system of manipulating input variables and determining the behaviour of the human body in conditions simulating an environment that cause injury ${ }^{12}$.

A collated set of desirable attributes for a computational model of a human structure were proposed by McKee et al. ${ }^{143}$ and, it was stated that: inverse dynamics, forward dynamics, relevant anatomy and physiology, contact resolution, and relevant performance ranges were pertinent considerations for any model.

\section{Inverse Dynamics Simulation}

Inverse dynamics requires body movement parameters to determine muscle excitations. Noninvasive measurements of body motions such as position, velocity, acceleration, and external loads are measured as inputs to calculate muscle force $\mathrm{e}^{140,144}$.

Generally the inputs are collected from data driven approaches which model exterior human geometries deformed by the underlying muscle. The approach generally uses range scanning techniques or surface skin marker systems to gather profiling data for a given pose ${ }^{94}$. Force measuring in simulation at the human interface with external entities is used to collect complementary data (e.g. force plates mounted to the ground are generally used to determine ground reaction forces in the gait cycle, as measurement of the isometric muscle effects without joint changes remains an issue ${ }^{140}$ ). The collected input data is then used alongside 
known body segment data such as the axes of joints and inertial properties of the segments to calculate joint torques $^{144}$.

In the human body, the number of muscles spanning a joint is generally more than is mechanically necessary to perform the function; therefore a shared joint torque is achieved. An optimisation strategy is commonly used to estimate individual muscle function and deal with the redundancy in the system. In most cases it is optimised by minimising a force related objective function such as the sum of muscle forces or stresses ${ }^{119,145}$.

\section{Forward Dynamics Simulation}

Forward dynamics involves the use of muscle excitations to determine human movement. Muscle activation patterns or muscle forces are used as inputs for the equations of motion, which are integrated, resulting in joint torques and motion of the body segments ${ }^{144}$. The resultant system achieved is under-determined therefore muscle forces are optimised to determine the required output criteria (e.g. maximal jump height).

The integration of the equations of motion however, is computationally expensive and time consuming, depending on the model complexity; it can take days or even weeks on a modern computer to converge. Anderson \& Pandy ${ }^{146}$ used dynamic optimisation to compute the activation patterns of muscles, the convergence took nearly 800 hours on a single processor.

Furthermore many studies use an unrealistic optimisation approach to deal with the redundancy of muscles in the system ${ }^{144}$. In a musculoskeletal model it is important that each muscle is characterised accurately and the correct amount of force is attributed to each muscle. However in many models the muscle force is restricted to a value between and a static maximal force based on the physiological cross-sectional area (PCSA) ${ }^{147-149}$. Therefore

muscle force can drop instantaneously from maximal force to zero ${ }^{149-152}$. Although, excitation and activation dynamics actually restrict the transitions in muscle force ${ }^{144}$. 


\section{Relevant Anatomy and Physiology}

The outcome of a computational model is highly dependent on the quality of the anatomical model parameters. The geometry defined from a dataset defines the path of the musculotendon complex during a movement. Force generating properties such as optimal fibre length, physiological cross sectional area (PCSA), pennation angle and tendon length specify the maximal amount of force in the muscle and thus are necessary to accurately characterise behaviour ${ }^{144,153}$.

A musculoskeletal model should accurately represent the mechanical tissue properties of the investigated subject. Discrepancies between the model and the subject lead to inaccurate model outputs. One of the main areas where materials data require further characterisation is under high strain rate loading conditions as tissue properties change dramatically under these conditions $^{12,154}$.

Muscle models are generally over simplified by neglecting non-uniformity and irregularity that clearly present in the architecture of real muscle specimens. The reason may be due to limited availability of data and unknown physiological properties ${ }^{140}$. For example, in most studies the material properties of cortical bone are assumed to be homogenous, while in reality they are inhomogeneous ${ }^{155,156}$. To acquire an estimation of the inhomogeneous properties of bone, CT scans are needed.

Initial determination of muscle parameters was conducted through dissection of PMHS to determine the force generating characteristics of the muscle by obtaining properties such as muscle mass ${ }^{157-159}$ and PCSA ${ }^{34}$. PMHS still have wide applicability and are currently the standard measures for characterising muscle architecture within the field ${ }^{160,161}$.

Most musculoskeletal models use published generic datasets as the basis for determining the anatomical parameters of the computational model. However existing datasets are often 
incomplete and focus on a specific research field (e.g. Wickiewicz et al. ${ }^{162}$ reported the sarcomere length of 27 muscles in a dataset of the lower extremity together with muscle parameters, however not all the muscles in the lower extremity were considered). In other studies important parameters such as joint parameters, muscle attachment sites and optimal muscle fibre angles are absent. In an ideal scenario, the anthropometric parameters are subject specific to account for architectural differences between subjects ${ }^{144}$. Currently, the most frequently used and complete data sets currently being used ${ }^{163,164}$ were collated from a combination of several pre-existing datasets ${ }^{144}$. It is therefore difficult to conclude whether the result is generic representation of a particular demographic or merely a convenient ‘virtual Frankenstein’s monster’.

Human volunteers are also still used to characterise external body geometries; Vezin \& Verriest ${ }^{165}$ took 50 anthropometric measurements through palpation of anatomical landmarks on body segments in order to define the orientation of body segments. However, primarily volunteer data only has applicability in movement studies, as only external surface parameters can be measured.

In recent years imaging techniques such as MRI and CT have been used extensively due to the improved accuracy of the scans ${ }^{166}$. MRIs generally have the greatest overall utility as they are suitable for simultaneous examination of hard and soft tissues ${ }^{167}$. The use of MRI's has led to the emergence of more individualised, accurate and detailed musculoskeletal models ${ }^{7}$. The Visible Human Project ${ }^{168}$ is a human geometry database that included high quality MRI data that characterises segments of the human body with $1 \mathrm{~mm}$ cross sectional slices ${ }^{169}$. However the generated model is only valid in the one measured position and will cause errors when extrapolated to other positions ${ }^{144}$. It should also be noted that the position was prone and post-mortem. The major issue with a generic dataset is that it is inherently not 
individualised and therefore will not accurately represent any individual member of the target population $^{8}$.

Furthermore, clinical MRI datasets present large amounts of textural information, noise, and low resolution artefacts ${ }^{167,170}$. Horsman et al. ${ }^{144}$ stated that muscle parameters such as optimal fibre length, sarcomere length and attachment sites are difficult to recognise using MRI data. In many cases anatomical modelling also requires significant use and interaction and is therefore extremely time consuming ${ }^{171-173}$.

One of the key areas for future developments in the field is centred on dynamic imaging techniques, which have demonstrated the capability to characterise the internal structures of a muscle in real time ${ }^{172,174}$. There are several dynamic imaging techniques that offer utility in computational modelling: dynamic MRI, Phase Contrast MRI and Diffusion Tensor Imaging all present the ability to model internal structures in this manner ${ }^{7,175-177}$.

\section{Contact Resolution}

With any computational model contact issues must be resolved to determine the interaction that occurs at the interface between tissues. Contact modelling refers to the study of the deformation of bodies. It has long been an active area of research in mechanics ${ }^{178}$; however it has wider usage and applicability within the fields of biomechanics and computer graphics ${ }^{179}$.

Contact modelling has been extensively researched over the past few decades ${ }^{180-183}$, however issues still exist particularly in resolving multiple contacts with friction for both rigid and deformable bodies ${ }^{184}$ and thus fast and reliable algorithms for impact and friction remain open problems ${ }^{166,179}$. Consequently, trade-offs must be made between speed, numerical stability and accuracy ${ }^{185}$. 
In the human body contact problems exist in muscle groups or between muscles and the underlying skeleton ${ }^{140}$. Particular problem areas are joints where cartilage and synovial fluid provide friction resistance between joint contact surfaces ${ }^{166}$.

Collision detection is the first phase of solving contact problems, before applying collision dynamics the potential contacting points or vertices must be checked. There are several different factors which influence collision detection; the object geometry is a particular key consideration. In general most objects are represented as simple geometric shapes consisting of simple elements (i.e. triangles, patches etc.). The elements are checked for proximity between each object pair ${ }^{166}$ using detection methods such as: relative object configuration, detection of intersections, distance calculations between objects and boundaries, computation of separation distance between colliding objects ${ }^{186}$.

The major focus in developing a method for contact problems is on the robustness and capability of describing multiple simultaneous contacts and impulsive contacts, and the capability of employing resistive forces to avoid body penetrations ${ }^{166}$.

\section{Relevant Performance Ranges}

The computational model must exhibit behaviour within the human response corridor for a given set of inputs and environmental conditions. This must be achieved through controlling muscle contraction and/or neural activation.

The direct measurement of muscle force, however, is impractical due to ethical and legal concerns with measuring in vivo muscle forces on humans ${ }^{153,187}$. Hence the direct validation of optimised muscle forces is not possible (e.g. EMG and in vivo measured joint compression forces are used for evaluation of the validity of estimated muscle force ${ }^{144}$ ). EMG has some innate flaws though when measuring muscle force, it provides an indication of whether a muscle is active, but it is not considered an accurate measure of the muscular force patterns 
and magnitudes of force in dynamic movements ${ }^{188}$. There are several issues that exist in using EMG to represent force:

i) The Relationship between muscular forces and EMG is non-linear ${ }^{189}$

ii) There is a temporal disassociation between the muscle and EMG signals due to electromechanical delay ${ }^{155}$

iii) The EMG cannot indicate the contribution of an individual muscle to an observed motion $^{188}$

iv) Cross talk is often recorded from adjacent muscles ${ }^{190}$.

The ultimate goal of computational modelling in injury biomechanics research is a unified model, scalable from consistent geometries with the ability to accurately predict injuries from omnidirectional impacts. The rapid advancement in computer technologies shown in the past two decades serves as a good indicator of future growth in the area. Development in computer hardware and software increases the potential capabilities of future computational models $^{154,165}$.

Computational models are generally categorised relative to their complexity into the following groups: lumped mass models, multi-body models and discrete element models ${ }^{154}$.

\subsection{Lumped Mass Models}

Lumped mass models consist of concentrated masses connected with massless single dimensional springs and Newtonian dashpots ${ }^{2,140}$. They aim to represent the basic dynamic response of a human during an impact. However, lumped mass models are restricted by their simplicity and thus have limited application where environmental loading conditions become too complex ${ }^{2}$. 


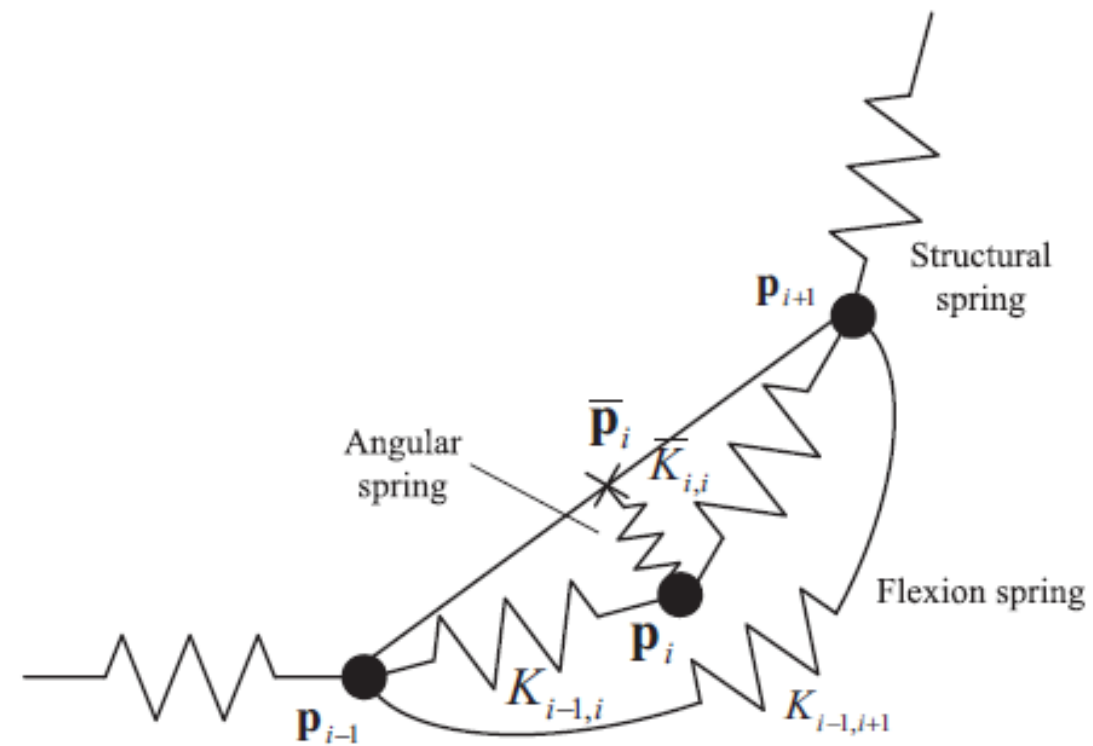

Figure 4 - Lumped Mass Model of Human Tendon ${ }^{191}$

\section{Muscle Models}

There are two fundamental types of muscle model that are commonly used: a phenomenological model ${ }^{192}$ and a biophysical cross-bridge model ${ }^{193}$.

\section{(a) Hill Model}

The Hill model is one of the first mathematical models and is based on systems engineering principles. It is used to represent the dynamic properties of a muscle based on experimental observations of controlled muscle inputs and outputs (muscle length, load and stimulation) $)^{192}$.

The model (Fig. 5) consists of a contractile element (CE) which represents the active force generating properties of the muscle and elastic elements to represent the passive muscle structures; a series elastic element (SEE), which represents the contribution of the tendon, aponeuroses and stretch of the cross-bridges connecting the myofilaments; and a parallel elastic element (PEE), which represents the passive connective tissue parallel to the contractile element ${ }^{144}$. 
The model proposed by Hill has been modified and extended most notably by Hatze ${ }^{194}$ that included viscoelastic properties and the influence of fibre length on the muscle activation process $^{195}$.

The Hill model is often used to predict force, length, and velocity relationships in a computationally efficient way and thus has application in movement analysis and muscle performance ${ }^{163,196-201}$. However since it's a descriptive lumped parameter model it cannot be used to study microscopic processes in the muscle ${ }^{144,191,195}$.

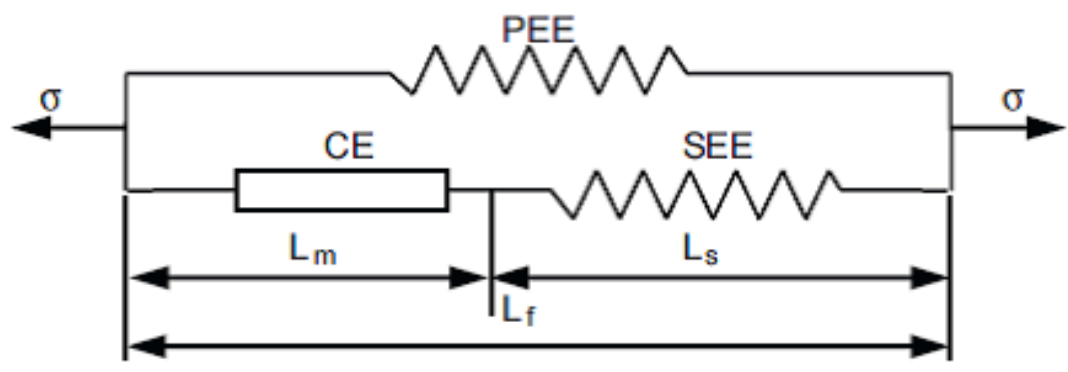

Figure 5 - Hill Model

\section{(b) Huxley Model}

The Huxley model considers the actual molecular structure of the muscle and describes the dynamics of the tissue based on the number of cross-bridges ${ }^{193}$. The model is based on an assumed probability of attachment and detachment of the myosin head to the actin filament as a function of the stretch of the myosin head ${ }^{144}$.

Therefore, using the stiffness of the cross-bridges and the length distribution of each crossbridge population, the force in each filament can be determined in time, which sums up to the total of muscle force.

The model results in a good fit with experimental force-velocity curves and is therefore suitable to study muscle force transitions. Yet the force-length relation and activation dynamics are not described. In addition, a very high computational burden limits its utility and has thus far made such models unsuitable for implementation in comprehensive 
musculoskeletal models ${ }^{144}$. Huxley models have been mainly used to understand the properties of the microscopic contractile elements ${ }^{191}$.

Many early lumped mass human body models were based on rigid skeletons ${ }^{202,203}$ as they were straightforward to implement. These models often represented muscles as single lines from origin to insertion ${ }^{148,204-206}$ and used physical models, such as elastic threads attached to skeletons to visualise muscle paths ${ }^{207,208}$. However line segments frequently make inaccurate assumptions about how a muscle changes shape as it interacts with the underlying muscles, bones, and other structures as joints move and thus do not provide a good representation of the muscle ${ }^{7}$.

In most models, muscle morphology is greatly simplified and, the muscle is generally described by 1-3 muscle elements, when in reality, to accurately describe the mechanical effect of a muscle a minimum of 6 muscle elements are required to simulate the pulling forces on bones ${ }^{200,209}$. More sophisticated muscle attachment simulation may lead to further enhancement of muscular force estimation, which in turn may result in more accurate bone strain estimation ${ }^{188}$.

Other inaccuracies result from the fact that many muscles that curve around intervening structures are inaccurately represented; these muscles are defined as straight muscle elements which result in inaccuracies in muscle moment arm, length and velocity, which are important parameters for the estimation of muscle force ${ }^{144}$.

The first dynamic response muscle system was developed by Chadwick et al. ${ }^{210}$ who linked free form deformations (FFDs) to point masses in a mass-spring system. Through using FFDbased muscle models with a mass-spring system the viscoelastic properties of muscle were represented ${ }^{154}$. However this model is physically unrealistic and its application is primarily limited to expressing the bulging effect over joints ${ }^{140}$. 


\subsection{Multi-Body Models}

A multi-body system consists of a number of interconnected bodies, which can be flexible, rigid or a combination of both. These bodies are connected together by means of kinematic joints described mathematically by constraint equations ${ }^{188}$. The motions of the jointed elements due to external forces are generated through force-interaction models.

Multi-body models are used in a wide range of industrial applications (e.g. robots, bridges, satellites) as well as bio-dynamical systems (such as human body, animals and insects) ${ }^{188}$. Multi-body human body models are typically more complicated than industrial multi-body systems, as human body models require a large variety of joint properties and articulations, body forms and complex actuators in the forms of muscles and neighbouring soft tissue ${ }^{211}$.

The Hill and Huxley muscle models are used as the predominant basis for describing the actions of muscles in multi-body models. The first published human multi-body model was developed by McHenry ${ }^{139}$ for evaluations of vehicle restraint systems and vehicle crash responses. The model consisted of a limited number of linkages and joints embedded in the software; it was 2-dimensional and had 7 degrees of freedom ${ }^{154}$.

In recent years biomechanical models based on multi-body dynamics have been used widely in the analysis of human physical activities ${ }^{212}$. Models have been developed for investigation of human function. Anderson \& Pandy ${ }^{146}$ and Nagano et al. ${ }^{213}$ both developed models simulating human jumping consisting of rigid body segments and muscular activators whilst Delp et al. ${ }^{163}$ developed a lower extremity rigid body model to study the biomechanical consequences of surgical reconstructions ${ }^{188}$.

Multi-body software simulation packages have been developed to provide a framework from which universal musculoskeletal models can be developed. They have been used since the 
early 1970’s in general engineering applications using software packages such as ADAMS (Automatic Dynamic Analysis of Mechanical Systems) and DADS (Dynamic Analysis and Design Software).

In recent years, software packages have been developed specifically for musculoskeletal modelling. SIMM (Software for Interactive Musculoskeletal Modelling) ${ }^{163,214,215}$, Anybody $^{216}$, Lifemod, and VIMS (Virtual Interactive Musculoskeletal System) ${ }^{196}$ are some of the most widely used software packages.

SIMM was the first graphics based software for development and analysis of musculoskeletal models ${ }^{144}$. It is a rigid body model that lets users create, alter and evaluate human graphics simulation models of almost any musculoskeletal structure ${ }^{188,215}$. The model has wide applicability within the medical industry; it has been used to study the biomechanical consequences of surgical procedures ${ }^{217}$ such as bone reconstructions, joint replacements and muscle-tendon surgeries.

However, simulation software has many limitations, which are primarily based on its simplifying assumptions. Each muscle-tendon is defined as path of line segments, which is unrealistic for large complex muscles that have several points of attachment. The models typically assume that all fibres are the same length for a given muscle-tendon length, which may provide an underestimation on the joint angle over which the muscle can produce force. They also inherently limited by the biomechanical data on which model parameters are based $^{163}$.

In general, multi-body models provide an efficient balance of accuracy relative to computational costs. They are particularly useful in scenarios where optimisation and parameter sensitivity are involved, which would be too computationally expensive to model with discrete element models and not presented in sufficient detailed enough using lumped 
mass models. However, multi-body models are limited by their lack of failure descriptions at tissue level, simple approximations of contact forces, and inability to accurately model body deformation as they have to rely on interpretation of trauma using structural injury criteria, which has been tailored to ATDs not computational models ${ }^{2}$.

\subsection{Discrete Element Models}

Discrete element models are the most sophisticated and accurate computational models ${ }^{191,218}$. The finite element method (FEM) is a powerful tool for finding approximate numerical solutions through transforming partial differential equations into a set of algebraic equations $^{141}$.

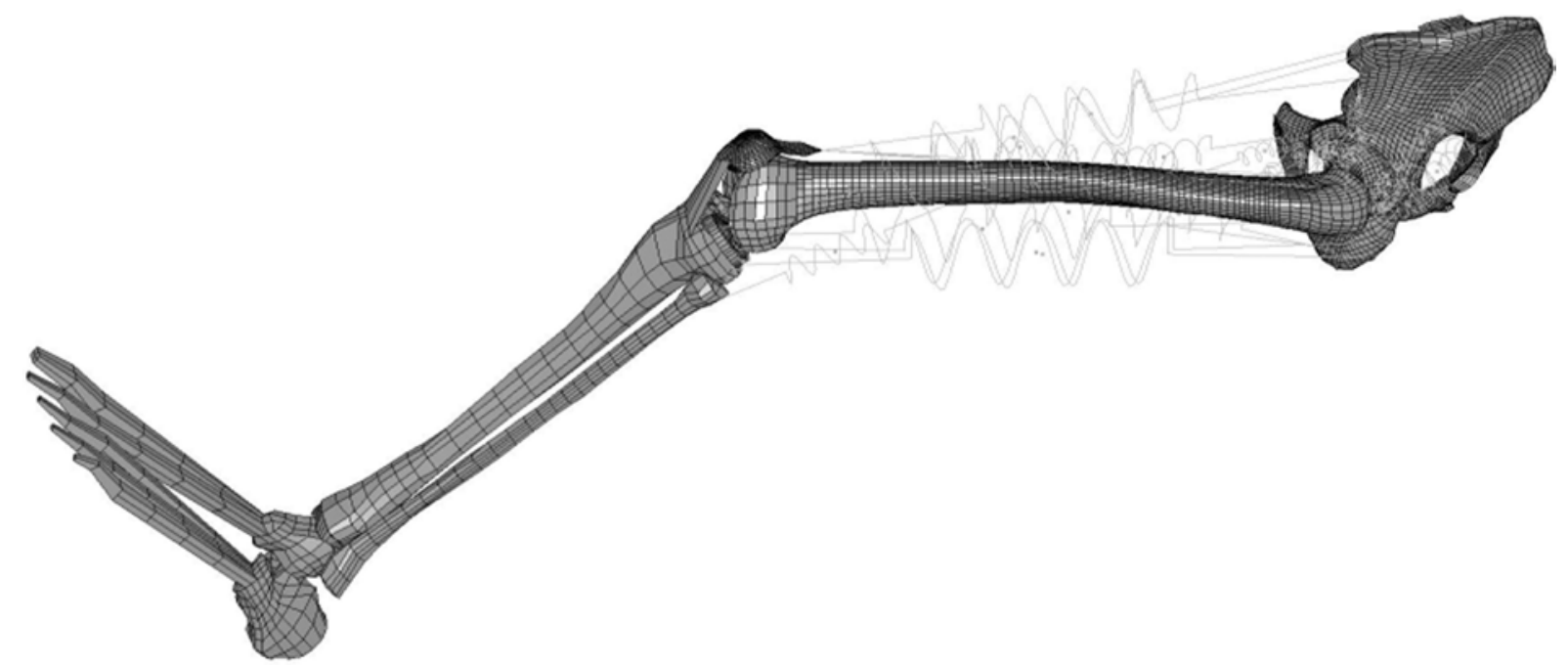

Figure 6 - FE Model of a Human Leg with Simulated Muscles and Ligaments ${ }^{169}$

In the FEM the body is divided into a series of finite volumes, surfaces or lines interconnected at points called nodes, which together form the model mesh. Most FE models are typically displacement based. The displacements and positions of the elements are determined by interpolation functions, which are often selected based on their geometry, accuracy and computational budget. Stresses are determined through deformations and 
constitutive properties of the materials modelled. The material models are assigned to each of the elements corresponding to the associated tissues to define the mechanical properties ${ }^{140,154}$.

Given a dynamic problem to be solved, equilibrium equations are derived in terms of quantities of interest (e.g. stress or strain) and are expressed as partial differential equations (PDEs). These PDEs are then approximated by the FEM ${ }^{140}$.

Finite element models require detailed descriptions of internal and external anatomical features to improve their geometrical accuracy ${ }^{219-223}$. Therefore three-dimensional imaging techniques such as MRI and CT are commonly used to characterise accurate datasets ${ }^{188}$.

The muscle strains calculated from both the Hill-based models and the Huxley-based models are single dimensional, it is therefore difficult to generalise these models for predicting nonuniform deformation of skeletal muscles with complex 3D geometry and anisotropic properties ${ }^{191}$. Hence morphological models are generally used to describe more detailed musculoskeletal interactions as the models give additional credence to structural characteristics $^{191}$.

Morphological models consider structural and more complex geometrical aspects of the muscle such as aponeuroses and fibre orientation. These models aim to predict muscle deformation and the isometric muscle force given the muscle length based on the assumption that a muscle has a constant muscle volume during contraction. With the optimal fibre length and pennation angle, the force-length characteristics of the muscle can be determined ${ }^{144}$.

Consequently FE models have several advantages over simpler model types. They are capable of modelling anisotropic, inhomogeneous, non-linear tissues that are present in the human body. They are also capable of modelling delineated stress distributions across tissues 
that allow for injury predictions based on local values of stress and strain and thus are capable of determining deformations, forces, pressures, and alignments ${ }^{2,188}$.

Muscle models using FEM have been widely researched ${ }^{141,172,218,224,225}$, however they still presents one of the biggest challenges in the field. Several researchers have proposed models, with specific focus on replicating muscle shape and its deformable behaviour. For example, Yucesoy et al. ${ }^{218}$ modelled the mechanical behaviour of skeletal behaviour as the interaction between the intercellular domain (i.e. muscle fibres) and the extracellular domain (i.e. elastic tissue). The domains were modelled with two separate meshes and elastically linked to account for the trans-membranous attachments and to permit force transmissions between domains.

Blemker \& Delp ${ }^{172}$ also developed a novel representation of complex muscle geometry and architecture. A variation of moment arms of fibres and hyper elastic material properties were coupled using the strain energy approach. They demonstrated that different types of contraction and effects of muscle geometry and fibre orientation on stress distribution can be incorporated into the Huxley model to represent contractile properties of skeletal muscle ${ }^{140}$. Ng-Thow-Hing \& Adviser-Fiume ${ }^{222}$ proposed a more sophisticated model of the human soleus muscle based on anatomical and biomechanical considerations. The solid muscle was extracted from medical imaging data or cross-sectional sliced images (e.g. Visible Human Project) and modelled using volumetric B-splines. While a Hill-based model is employed to express the dynamics of muscle fibre, a mass-spring system is used to represent the viscoelastic deformation of muscle ${ }^{140}$.

In most musculoskeletal models, muscle tissues are represented by viscoelastic materials due to the viscous and elastic nature of human biological tissues. The most commonly used 
materials models are the Maxwell model, the Kelvin-Voigt model, and the Burger model; biphasic, poroelastic, and triphasic material models are also used ${ }^{166}$.

FE models present the most complex and accurate means of determining human response. The ability of models to accurately predict local stresses and strains based on controlled external loading conditions is useful in the development of more refined injury threshold criteria. In addition, computational models can be tested at sub-injurious levels, which can lead to a greater understanding of human response under failure loads ${ }^{154}$.

However, one of the major potential limitations of FE models is that they are heavily dependent on the quality of the human model with regards to form and material properties; this affects the accuracy of the results ${ }^{226}$. Hence, experimental verification is often considered a necessity.

The computational cost of FE models is another pertinent consideration. Higher order interpolation functions and more complex elements require greater computation per element, which can be time consuming and costly ${ }^{140,166}$. Lin et al. ${ }^{227}$ reported that a simple elastic foundation contact model, will take an average CPU 5-10 minutes for one cycle of dynamic simulation, which can be very computationally expensive in an optimisation requiring thousands of cycles. Specifically considering the human body, finite element analysis (FEA) of a bone is very computationally expensive due to the complex geometry of the structure, the fine element meshes and large number of nodal degrees of freedom required. This has meant that FEA is typically restricted to a piece of bone or a single bone ${ }^{188}$.

Furthermore, due to expensive computation, finite element models usually need to be applied in a static or short term dynamic solution, as they are considered computationally impractical to be used in dynamic analysis where a number of bones and muscles as well as interactions need to be taken into consideration ${ }^{188}$. 
For a model to provide accurate information it must be validated against experimental data, however currently there is insufficient data available from organic surrogates to fully validate the models and thus their response patterns may be inaccurate and unrepresentative of human behaviour $^{12,140,144,154}$. Furthermore much of the data used to validate existing models was not acquired for the purposes of validation and therefore likely have inherent differences in the experimental protocol ${ }^{154}$. Therefore, complex simulations must rely on assumptions and simplifications to deal with the nondeterministic nature of the equations driving the dynamics $^{228}$.

Specific areas where data are lacking concern physiological responses of the human body such as the activation range of muscles, fatigue, and muscle tonicity, which cannot be gained from PMHS data ${ }^{140,165}$.

Crandall et al. ${ }^{2}$ has expressed these problems succinctly when he states "At best FE models approximate human response based on a set of simplifying assumptions. At worst they provide an accurate representation of inaccurate data if proper procedures for verification and validation are not followed”.

When considering computational models as an appropriate sports impact surrogate it is to be noted that they have the theoretical capability to embody all of the sports specific surrogate requirements. Computational models can potentially have highly biofidelic external human geometries and given appropriate material models and data all major tissue structures can be modelled and evaluated at tissue level, and the surrogate is designed for repeat impact as no physical damage is incurred through trials, all feedback can be obtained without affecting the biofidelity of the surrogates. 
One of their great advantages is that they can potentially simulate very complex scenarios, with many interacting tissues and environmental conditions. They also have no physical material cost and hence permit easy manipulation of variables.

However, there are practical limitations associated with their use. Constructing the model is time consuming and the computational cost severely restricts their application. Generally this is so substantial that trials are limited to small body segments or single tissue structures. The lack of validation data also severely restricts confidence in the accuracy of the predictions.

The greatest utility of computational models in sports injury evaluation is through the ability to model complex structures and loading conditions. Without more extensive verification their main use at this time is perhaps not so much to provide absolute values but to explore and so better understand the potential interaction of complex structures and multiple phenomena. In studies which utilise complex geometries of strikers, targets and PPE, they are important in providing a good approximation of general human behaviour.

\section{CONCLUSIONS}

Surrogate models of human subjects are required for impact evaluation of PPE and determination of injury mechanisms. Considering the requirements for a surrogate of this type, it is important that it embodies the same size and shape as the target human, whilst responding consistently to repeat impacts and providing feedback from which to evaluate injuries.

Each type of surrogate has its individual merits and specific applications where it is particularly important in sports impact scenarios. In general, every type of surrogate discussed is useful in gaining a fuller understanding of the conditions experienced in a sports impact injury event and the subsequent behaviour of the human target body. 
Organic surrogates are inherently poor candidates for an impact surrogate as they are biological and hence not durable enough to withstand repeat injurious loads without degradation in tissue properties. The consistency and repeatability of responses are a key requirement in sports impact testing; this cannot be achieved using organic surrogates. The ethical and logistical constraints associated with testing organic surrogates also complicate matters and limits their utility as a primary impact surrogate.

Organic surrogates are however useful in the validation of artificial substitutes, providing key human behavioural response data that is used in the development of surrogate human tissues, determining specific physiological information that cannot be obtained with artificial surrogates.

Using human volunteers, there remains some scope to conduct useful PPE performance testing where steps are taken to minimise the risk of injury. There is some limited opportunity to further explore tissue responses in living humans where permanent or severe injury risks are kept to an ethically acceptable minimum. For the most part though, these activities will support research beyond safe loading thresholds using other surrogate technologies or approaches.

Animal surrogates have no foreseeable application in the injury and PPE evaluation domain. Given the high profile fashion conscious arena in which many brands operate there is no appetite to engage in PPE evaluation or tissue studies requiring experiments on animals.

PMHS similarly present many ethical issues. For injury and PPE evaluation, they provide the closest representation of human tissue structures and geometries and hence enable the determination of material properties and selection of a human tissue material simulant for synthetic or virtual surrogates but similar to animal surrogates many brands are unlikely to 
engage directly in testing activities with surrogates of this type which may be perceived unfavourably by their customers.

Artificial surrogates present a preferable solution for experimental impact testing as studies can be performed without harming the participants. Although they inherently lack many of the tissue complexities and biofidelity present in organic surrogates, artificial surrogates provide a consistent, repeatable means of determining human response.

Computational models are useful in that they are capable of modelling complex scenarios where there are many variables and environmental conditions influencing the subject. There is also no physical material cost and as such are flexible and permit manipulation of variables without having to fully reproduce the model. They are particularly useful in sports applications where specific design optimisations can be evaluated before prototypes are manufactured. They are also useful in enhancing understanding into performance phenomena and unobservable equipment and surrogate interactions at levels of detail beyond what can be physically measured.

However, to model a complex piece of anatomy and detailed environmental conditions (e.g. human lower leg for football stud impacts) the computational expenditure to solve the model is very high. This introduces large initial capital costs for equipment to cater for this. Despite their potential complexities, computational surrogates are undermined by the quality of the input data, particularly material models, which often negates any theoretical advantage.

On-going research and development of more detailed structurally sophisticated models with superior material models and software and hardware capable of handling the associated computational burden in a time and cost effective manner will, in time, result in greater use in the leading brand PPE domains (e.g. footwear). 
Synthetic surrogates provide a physical body that can be used to attach PPE and a means of determining effectiveness of the garment and measures of injury evaluation through instrumentation and feedback mechanisms that can be linked to specific injury outcomes. They are often used to either to validate computational models or where the computational capacity required and the expertise to undertake the analysis is too expensive.

For the testing of PPE and exploration of injury below catastrophic or permanent levels durable mechanical surrogates are the most likely to provide a cost effective platform for future research and development. Greater sophistication with regards to the materials and structures are required to model subtler, more sensitive injury types. Scenarios where repeat impact testing is necessary (e.g. cyclic fatigue testing of a garment of PPE) dictate that a mechanical surrogate would be required to provide a consistent and reliable response to impact without degradation in the surrogate's properties through its useful life. Standardised PPE acceptance testing is also a pertinent consideration in many industries; this requires a consistent testing medium.

Frangible surrogates should be considered in impact scenarios likely to result in permanent injury where it is necessary to use a greater complexity of tissue structures and biofidelity in response (e.g. head injuries in cricket, or knee injuries in snow sports). The increased severity of these injuries means that the increased cost associated is often a necessary compromise.

The failure of synthetic and virtual surrogates should not be either/or solutions but rather as complementary tools that together promote confidence in a deeper analytical complexity through thorough practical evaluation. Through a parallel cyclic development of both model types it is possible to develop a greater understanding of injury phenomena. For example, computational models run design optimisations for synthetic models that provide a fast and 
effective method for determining the accuracy of parameters, whilst synthetic models provide a method of physically validating parameters for virtual surrogates.

The idealised solution for a impact surrogate will involve a fully validated set of computational and synthetic models which provide kinetic and kinematic feedback of the injury event which can be directly linked to specific injury mechanisms. The progression towards more biofidelic models should be staged and consider advancement through predetermined levels of complexity, which are constantly validated. Specific focus must be placed on human tissue characterisation and determination of synthetic tissues and material models that represent their properties under impact conditions (e.g. tensed, fatigued muscle). 


\section{REFERENCES}

(1) Viano DC, King AI, Melvin JW, Weber K. Injury biomechanics research: an essential element in the prevention of trauma. J Biomech, 1989; 22 (5):403-417.

(2) Crandall JR, Bose D, Forman J, Untaroiu CD, Arregui-Dalmases C, Shaw CG, Kerrigan JR. Human surrogates for injury biomechanics research. Clinical Anatomy, 2011; 24 (3):362371.

(3) Mizuno Y. Summary of IHRA pedestrian safety WG activities - proposed test methods to evaluate pedestrian protection afforded by passenger cars. Proceedings of the 18th international conference on the enhanced safety of vehicles (ESV), 19-22 May 2003, Nagoya, Japan, 2003. Paper Number 05-0138.

(4) Noorpoor A, Abvabi A and Kiasat MS. Development a New Model of EEVC/WG17 Lower Legform for Pedestrian Safety. Proceedings of World Academy of Science, Engineering and Technology, Volume 31, 31 July 2008, ISSN 1307-6884, 2008. 191-198.

(5) Sato Y, Sasama T, Sugano N, Nakahodo K, Nishii T, Ozono K, Yonenobu K, Ochi T and Tamura S. Intraoperative simulation and planning using a combined acetabular and femoral (CAF) navigation system for total hip replacement. Medical Image Computing and Computer-Assisted Intervention-MICCAI 2000, October 11 - 14, Pennsylvania, USA, Springer, 2000. 227-233.

(6) Schmitt J, Meiforth J, Lengsfeld M. Development of a hybrid finite element model for individual simulation of intertrochanteric osteotomies. Med Eng Phys, 2001; 23 (8):529-539.

(7) Blemker SS, Asakawa DS, Gold GE, Delp SL. Image-based musculoskeletal modeling: Applications, advances, and future opportunities. Journal of magnetic resonance imaging, 2007; 25 (2):441-451.

(8) Scheepers F, Parent RE, Carlson WE and May SF. Anatomy-based modeling of the human musculature. Proceedings of the 24th annual conference on Computer graphics and interactive techniques, 3 - 8 August, Los Angeles, USA, ACM Press/Addison-Wesley Publishing Co., 1997. 163-172.

(9) Owens BD, Kragh Jr JF, Macaitis J, Svoboda SJ, Wenke JC. Characterization of extremity wounds in operation Iraqi freedom and operation enduring freedom. J Orthop Trauma, 2007; 21 (4):254-257.

(10) Ramasamy A, Hill A, Clasper J. Improvised explosive devices: pathophysiology, injury profiles and current medical management. JR Army Med Corps, 2009; 155 (4):265-272.

(11) Mckay BJ. Development of lower extremity injury criteria and biomechanical surrogate to evaluate military vehicle occupant injury during an explosive blast event.[dissertation], Wayne State University; 2010.

(12) Ramasamy A, Masouros SD, Newell N, Hill AM, Proud WG, Brown KA, Bull AMJ, Clasper JC. In-vehicle extremity injuries from improvised explosive devices: current and 
future foci. Philosophical Transactions of the Royal Society B: Biological Sciences, 2011; 366 (1562):160.

(13) NATO. Test Methodology for Protection of Vehicle Occupants against Anti-Vehicular Landmine Effects, RTO Technical Report, National Technical Information Service, Springfield, United States, April 2007, RTO-HFM-090.

(14) McIntosh AS. Biomechanical considerations in the design of equipment to prevent sports injury. Proceedings of the Institution of Mechanical Engineers, Part P: Journal of Sports Engineering and Technology, 2011; 226 (3-4):193-199.

(15) Wendt D, Van Loon LJC, van Marken Lichtenbelt WD. Thermoregulation during exercise in the heat: strategies for maintaining health and performance. Sports medicine, 2007; 37 (8):669-682.

(16) Shapiro Y, Seidman D. Field and clinical observations of exertional heat stroke patients. Med Sci Sports Exerc, 1990; 22 (1):6.

(17) Harris D, Spears I. The effect of rugby shoulder padding on peak impact force attenuation. Br J Sports Med, 2010; 44 (3):200-203.

(18) Pain MTG, Tsui F, Cove S. In vivo determination of the effect of shoulder pads on tackling forces in rugby. J Sports Sci, 2008; 26 (8):855-862.

(19) Usman J, McIntosh AS, Fréchède B. An investigation of shoulder forces in active shoulder tackles in rugby union football. J Sci Med Sport, 2011; 14 (6):547-552.

(20) Quarrie KL, Hopkins WG. Tackle injuries in professional rugby union. Am J Sports Med, 2008; 36 (9):1705-1716.

(21) Halkon B, Webster J, Mitchell S and Mientjes M. Development of a test methodology for the assessment of human impacts in sport. 9th Conference of the International Sports Engineering Association (ISEA), 9-13 July 2012, Lowell, Massachusetts, USA, Elsevier, 2012. 813-818.

(22) Penrose T, Foster D, Blanksby B. Release velocities of fast bowlers during a cricket test match. Australian Journal for Health, Physical Education and Recreation, 1976; 71

(Supplement to Australian Journal for Health, Physical Recreation \& Education):2-5.

(23) Anders E, Myers S. Field hockey: Steps to success. 2nd Edition, Champaign, IL, USA: Human Kinetics Inc., 2008.

(24) Winter DA. Anthropometry. Biomechanics and Motor Control of Human Movement. Second ed.: John Wiley \& Sons Inc; 1990. p. 51-57.

(25) Francisco AC, Nightingale RW, Guilak F, Glisson RR, Garrett Jr WE. Comparison of soccer shin guards in preventing tibia fracture. Am J Sports Med, 2000; 28 (2):227-233.

(26) Ankrah S, Mills N. Performance of football shin guards for direct stud impacts. Sports Engineering, 2003; 6 (4):207-219. 
(27) BS:EN 13061:2009 "Protective clothing - Shin guards for association football players Requirements and test methods", British Standards Institute, United Kingdom, 8 August 2009.

(28) BS 6183-3:2000 "Protective equipment for cricketers - Part 3: Leg protectors for batsmen, wicketkeepers and fielders, and thigh, arm and chest protectors for batsmen.", British Standards Institute, United Kingdom, 15 February 2000.

(29) BS:EN 13546:2000 "Protective clothing - Hand, arm, chest. Abdomen, leg, foot and genital protectors for field hockey goal keepers and shin protectors for field players Requirements and test methods", British Standards Institute, United Kingdom, 10 May 2007.

(30) Kent R, Bass C. Experimentacion con animales (Experimentation With Animals). In: Arregui-Dalmases C, Luzon J, Segui-Gomez M, editors. Fundamentos de Biomecanica en las Lesiones por Accidente de Trafico. (Fundamentals of Biomechanics and Road Traffic Injuries). Second Edition ed. Madrid; 2007.

(31) World Medical Association. Declaration of Helsinki - Ethical Principles for Medical Research Involving Human Subjects. 2008; Available at: [http://www.wma.net/en/30publications/10policies/b3/]. Accessed December 9th, 2012.

(32) King AI, Viano DC, Mizeres N. Humanitarian benefits of cadaver research on injury prevention. J Trauma, 1995; 38 (4):564.

(33) Hrysomallis C. Surrogate thigh model for assessing impact force attenuation of protective pads. Journal of Science and Medicine in Sport, 2009; 12 (1):35-41.

(34) Weber C. Chirurgische Erfahrungen und Untersuchungen nebst zahlreichen Beobachtungen aus der chirurgischen Klinik und dem evangelischen Krankenhause zu Bonn: Mit neun Tafeln. Reimer, Berlin, 1859. 171-174, ISBN: 978-3-11-160405-3

(35) Messerer O. Uber Elasticitat und Festigcitat der menschlichen Knochen. Stuttgart: J. G. Cotta'schen Bunchhandlung. 1880. Cited in Nahum AM and Melvin J, Accidental Injury, Biomechanics and Prevention, New York, Springer-Verlag, 1993

(36) Bergeron DM, Anderson IB, Coley CG, Fall RW, Assessment of Lower Leg Injury from Land Mine Blast - Phase 1: Test Results using a Frangible Surrogate Leg with Assorted Protective Footwear and Comparison with Cadaver Test Data, Technical Report, Valcartier, Canada, February 2006, DRDC Suffield TR 2006-051.

(37) Cronin D, Williams K, Bass CRD, Magnan P, Dosquet F, Bergeron DM, van Bree JLMJ, Test Methods for Protective Footwear Against AP Mine Blast, Contributory Paper, Springfield, Virginia, USA, March 2004, NATO HFM-089/TG-024.

(38) Dionne J, Makris A, Nerenberg J, Blast Evaluation of Spider Boot Foot Protection System Employing Surrogates and Biological Specimens, Photos courtesy of Allen-Vanguard Corporation, testing conducted through the US LEAP program, Ottawa, Ontario, Canada, .

(39) Snyder R, Hodgson VR, Nahum AM, King AI, Burstein AH, McHenry RR, Patrick LM, Walt AJ, Wilson RF, Lange WA, Mertz HJ. Biomechanics and Its Application to Automotive 
Design P-49 - A Continuing Engineering Education Course developed by SAE Automobile Body Activity, Passenger Protection Committee," SAE Technical Paper 730413, 1973, doi:10.4271/730413

(40) Verriest J. Thorax and upper abdomen kinematics and tolerance levels and injury criteria. The Biomechanics of Injury Trauma, 1984 :251-275.

(41) Bergeron DM. Test Methodologies for Personal Protective Equipment Against AntiPersonnel Mine Blast, Technical Report, Springfield, Virginia, USA, March 2004, NATO RTO Technical Report TR-HFM-089.

(42) Mertz H, Patrick L, Investigation of the kinematics and kinetics of whiplash, SAE Technical Paper, February 1967, 670919. DOI: 10.4271/670919

(43) Krstic AR, Bergeron DM, Bourget D, Softley I, Neades D, Development of a Lower Leg Physical Model for Enhanced Soldier Survivability against Landmines, Technical Report, Edinburgh, South Australia, Australia, October, 2002, The Technical Cooperation Program, Key Technical Activity 1-35.

(44) Sakezles C. Synthetic Human Tissue Models Can Reduce the Cost of Device Development, Medical Device Technology Report, Florida, USA, January/February 2009, 20 (1): $32-4$

(45) Van Ee C, Chasse A, Myers B. Quantifying skeletal muscle properties in cadaveric test specimens: effects of mechanical loading, postmortem time, and freezer storage. J Biomech Eng, 2000; 122 (1):9-14.

(46) Ore LS. Design Requirements and Specifications: Dummy Lower Extremity Development Task, Event Report, NHSTA (US Department of Transportation, Washington, DC), 1992.

(47) Petit P, Portier L, Foret-Bruno J, Trosseille X, Parenteau C, Coltat J, Tarriere C and Lassau J. Quasistatic characterization of the human foot-ankle joints in a simulated tensed state and updated accidentological data. Proceedings of the 1996 International IRCOBI Conference of the Biomechanics of Impact, September 11-13 1996, Dublin, Ireland, 1997. 363-376.

(48) Shaw G, Crandall J, Butcher J. Comparative evaluation of the THOR advanced frontal crash test dummy. International Journal of Crashworthiness, 2002; 7 (3):239-254.

(49) Crandall J and Pilkey W. Preservation of Human Surrogates for Impact Studies. Proceedings of 13th Southern Biomedical Engineering Conference, Washington, Engineering Research Center, University of DC, Institute of Electrical and Electronics Engineers, 1994. 582-585.

(50) Menz LJ. Structural changes and impairment of function associated with freezing and thawing in muscle, nerve, and leucocytes. Cryobiology, 1971; 8 (1):1-13.

(51) Lee KE, Pelker RR. Effect of freezing on histologic and biomechanical failure patterns in the rabbit capital femoral growth plate. J Orthop Res, 1985; 3 (3):514-515. 
(52) Clavert P, Kempf JF, Bonnomet F, Boutemy P, Marcelin L, Kahn JL. Effects of freezing/thawing on the biomechanical properties of human tendons. Surgical and Radiologic Anatomy, 2001; 23 (4):259-262.

(53) Kent R, Lessley D, Sherwood C. Thoracic response to dynamic, non-impact loading from a hub, distributed belt, diagonal belt, and double diagonal belts. Stapp Car Crash J, 2004; 48:495-519.

(54) Guillotin B, Bourget C, Remy-Zolgadri M, Bareille R, Fernandez P, Conrad V, AmédéeVilamitjana J. Human primary endothelial cells stimulate human osteoprogenitor cell differentiation. Cellular Physiology and Biochemistry, 2004; 14 (4-6):325-332.

(55) Roach M. Stiff: The curious lives of human cadavers. 1st Edition, United States: WW Norton \& Company, 2003.

(56) Helelä T. Age-dependent Variations of the Cortical Thickness of the Clavicle. Annals of Clinical Research, 1969; 1 (2):140-143.

(57) Chaloner E, McMaster J, Hinsley D. Principles and problems underlying testing the effectiveness of blast protective footwear. Royal Army Medical Corps, 2002; 148 (1):38-43.

(58) Woo SLY, Hollis JM, Adams DJ, Lyon RM, Takai S. Tensile properties of the human femur-anterior cruciate ligament-tibia complex. The effects of specimen age and orientation. Am J Sports Med, 1991; 19 (3):217-225.

(59) Bergeron DM, Chichester C. Protecting Deminers from APLs: A Review of US/Canada Cooperation in R\&D. Journal of Mine Action: Miners, Manual Demining \& Personal Protective Equipment, 2003; 7 (1) 18 Pages.

(60) Human Tissue Act 2004 (Act of Parliament), Chapter 30, London: HMSO, 15 November 2004.

(61) Bir C, Barbir A, Dosquet F, Wilhelm M, van der Horst M, Wolfe G. Validation of lower limb surrogates as injury assessment tools in floor impacts due to anti-vehicular land mines. Mil Med, 2008; 173 (12):1180-1184.

(62) Geurts J, van der Horst M, Leerdam PJ, Bir C, Van Dommelen H and Wismans J. Occupant Safety: Mine Detonation under Vehicles - A Numerical Lower Leg Injury Assessment. 2006 International IRCOBI Conference on the Biomechanics of Impact, 22-26 September, Madrid, Spain, 2006.

(63) Kajzer J, Matsui Y, Ishikawa H, Schroeder G and Bosch U. Shearing and bending effects at the knee joint at low-speed lateral loading. 19th SAE International Congress and Exposition, March 1999, Detroit, Michigan, USA, Society of Automotive Engineers, 1999.

(64) Kajzer J, Schroeder G, Ishikawa H, Matsui Y and Bosch U. Shearing and Bending Effects at the Knee Joint at High Speed Lateral Loading. Proc. 41st Stapp Car Crash Conference, November 1997, Society of Automotive Engineers, Warrendale, PA., Reproduced by permission of The Stapp Association., 1997. SAE Paper No. 973326 
(65) Heald J, Pass D. Ball standards relevant to risk of head injury. In Hoerner E. F. (Ed.), Head and Neck Injuries in Sports, ASTM STP 1229. Philadelphia, American Society for Testing and Materials (ASTM), 1994: 223-238.

(66) Lowenhielm P, Voigt GE, Ljung CB, Wihlberg BG. Influence of post mortem changes on experimental safety belt injuries. Z Rechtsmed, 1977; 80 (3):171-182.

(67) Alexander R. Bipedal animals, and their differences from humans. J Anat, 2004; 204 (5):321-330.

(68) Cavalieri P, Singer P. The great ape project: Equality beyond humanity: St Martins Pr, 1993.

(69) Laboratory Animal Welfare Act 2006, P.L. 89-544, Washington, United States, 24 August 1966.

(70) Animal Welfare Act 2006, Chapter 45, London: HMSO, 8 November 2006.

(71) Mertz H. Anthropometric test devices. In: Nahum AM, Melvin JW, editors. Accidental Injury, Biomechanics and Prevention New York: Springer-Verlag; 2002. p. 89-102.

(72) Bedewi PG. A review of biomechanics in automotive safety. Int J Veh Des, 2001; 26 (4):407-429.

(73) Zhao J and Narwani G. Biomechanical Analysis of Hard Tissue Responses and injuries with Finite Element Full Human Body Model. Proceedings of the 20th International Technical Conference on the Enhanced Safety of Vehicles (ESV), 18-21 June, Lyon, France, U. S. Department of Transportation National Highway Traffic Safety Administration, 2007.

(74) Neilson L, Lowne R, Tarriere C, Bendjellal F, Gillet D, Maltha J, Cesari D and Bouquet R. The EUROSID side impact dummy. Tenth International Technical Conference on Experimental Safety Vehicles. NHTSA, July 1 - 4 1985, Oxford, England, 1985. SAE Paper No. 856029

(75) Gromer A, Stahlschmidt S and Schuster P. WorldSID Dummy Model Development in Cooperation with German Automotive Industry. International LS-DYNA Users Conference, June 8-10 , 2008, Detroit, United States, 2008. Paper No. 334

(76) Beach D, White R. Jr., Shams T and Rangarajan N. THOR Advanced Test Dummy Biofidelity and Injury Assessment. FAA International Aircraft Fire and Cabin Safety Conf. 16-20 November 1998, Atlantic City, New Jersey, 1998.

(77) Backaitis SH, Mertz HJ. Hybrid III: The first human-like crash test dummy. :Society of Automotive Engineers, 400 Commonwealth Dr, Warrendale, PA, 15096, USA, 1993.

(78) Kim A, Sutterfield A, Rao A, Anderson K, Berliner J, Hassan J, Irwin A, Jensen J, Kleinert J and Mertz H. A Comparison of the BioRID II, Hybrid III, and RID2 in LowSeverity Rear Impacts. Proceedings of the19th. International Technical Conference on the Enhanced Safety of Vehicles (ESV), 6-9 June 2005, Washington DC, United States of America, 2005. June, 2005. Paper No. 05-0225 
(79) Schneider L. Development of anthropometrically based design specifications for an advanced adult anthropomorphic dummy family, Final report, Ann Arbor, Mich: University of Michigan, Transportation Research Institute, 1983, Volume 1.

(80) Krstic A, inventor. Surrogate. Washington D.C, United States, 6,923,081, 2005, 2nd August 2005.

(81) Pheasant S, Haslegrave CM. Bodyspace: anthropometry, ergonomics, and the design of work: CRC Press, 2006.

(82) Peoplesize 1998. Open Ergonomics Ltd. [http://www.openerg.com/psz/index.html]. Loughborough Technology Centre, Epinal Way, Loughborough, Leics. LE11 3GE.

(83) Lin YC, Wang MJJ, Wang EM. The comparisons of anthropometric characteristics among four peoples in East Asia. Appl Ergon, 2004; 35 (2):173-178.

(84) Kuppa S, Haffner M, Eppinger R and Saunders J. Lower Extremity Response and Trauma Assessment using the Thor-Lx/HIIIr and the Denton leg in Frontal Offset Vehicle Crashes. 17th International Technical Conference on the Enhanced Safety of Vehicles, 4-7 June, 2001, Amsterdam, The Netherlands, 2001. Paper No. 456

(85) Manning J. Development Of A Pedestrian Legform To Assess Sensors Used In Active Pedestrian Protection Systems. Proceedings of the 20th International Technical Conference on the Enhanced Safety of Vehicles (ESV), 18-21 June 2007, Lyon, France, U. S. Department of Transportation National Highway Traffic Safety Administration, 2007. Paper No. 07-0271

(86) Owen C, Lowne R and McMaster J. Requirements for the Evaluation of the Risk of Injury to the Ankle in Car Impact Tests. 17th International Technical Conference on the Enhanced Safety of Vehicles, 4-7 June, 2001, Amsterdam, The Netherlands, 2001. Paper No. 318

(87) Denton RA, inventor. Crash Test Dummy Lower Leg Structure. United States, 4,488,433, 1984, 18th December 1984.

(88) Konosu A, Tanahashi M. Development of a biofidelic flexible pedestrian legform impactor. Stapp Car Crash J, 2003; 47: 459-472.

(89) Klinich KDS, Schneider L, University of Michigan. Transportation Research Institute, Alliance of Automobile Manufacturers, Biomechanics of pedestrian injuries related to lower extremity injury assessment tools: a review of the literature and analysis of pedestrian crash database, Literature Review, University of Michigan Transport Research Institute, September 2003, UMTRI-2003-25.

(90) Lawrence GJL and Hardy BJ. Pedestrian safety testing using the EEVC pedestrian impactors. 16th ESV Conference, May 31- June 4, 1998, Windsor, Ontario, Canada, 1998. Paper No. 98-S1O-0-03

(91) Mallory A, Stammen JA and Legault F. Component Leg Testing of Vehicle Front Structures. 19th International Technical Conference on the Enhanced Safety of Vehicles, 6-9 June 2005, Washington DC, USA, 2005. Paper No. 05-0194 
(92) Konosu A, Issiki T, Tanahashi M and Suzuki H. Development of a Biofidelic Flexible Pedestrian Legform Impactor type GT (Flex-GT). Proceedings of the 20th International Technical Conference on the Enhanced Safety of Vehicles, 18-21 June 2007, Lyon, France, 2007. Paper No. 07-0178

(93) Been B, Bermond F, Bortenschlager K, Hynd D, Martinez L, Ferichola G and Meijer R. WorldSID small female Side Impact Dummy specifications and prototype evaluation. 20th ESV, 18-21 June, 2007, U. S. Department of Transportation National Highway Traffic Safety Administration, 2007. Paper No. 07-0311

(94) Kimpara H, Lee J, Yang K, King A. Effects of Body Weight, Height, and Rib Cage Area Moment of Inertia on Blunt Chest Impact Response. Traffic Injury Prevention, 2010; 11

(2):207-214.

(95) Skelton C, Cannon L, and Trimble K. Development of a Lower Limb Physical Model to assess the severity of Land Mine injury. XXIII International Congress on Military Medicine, Jun 2000, 2000. 185.

(96) Bourget D, Bergeron DM, Williams K, Salisbury C, Cronin D, inventors. Simplified Biofidelic Lower Leg Surrogate. Canada, CA 2438950, 2000, 8-9 July 2000.

(97) Biokinetics and Associates Ltd. The Complex Lower Leg, July 2003.

(98) Yeni Y, Brown C, Norman T. Influence of bone composition and apparent density on fracture toughness of the human femur and tibia. Bone, 1998; 22 (1):79-84.

(99) Bensamoun S, Ho Ba Tho MC, Luu S, Gherbezza JM, de Belleval JF. Spatial distribution of acoustic and elastic properties of human femoral cortical bone. J Biomech, 2004; 37 (4):503-510.

(100) Carter DR, Hayes WC. Bone compressive strength: the influence of density and strain rate. Science, 1976; 194 (4270):1174-1176.

(101) Lotz JC, Gerhart TN, Hayes WC. Mechanical properties of trabecular bone from the proximal femur: a quantitative CT study. J Comput Assist Tomogr, 1990; 14 (1):107.

(102) Ward SR, Lieber RL. Density and hydration of fresh and fixed human skeletal muscle. J Biomech, 2005; 38 (11):2317-2320.

(103) Mendez J, Keys A. Density and composition of mammalian muscle. Metab Clin Exp, 1960; 9 (2):184-188

(104) Fidanza F, Keys A, Anderson JT. Density of body fat in man and other mammals. J Appl Physiol, 1953; 6 (4):252-256.

(105) Farvid M, Ng T, Chan D, Barrett P, Watts G. Association of adiponectin and resistin with adipose tissue compartments, insulin resistance and dyslipidaemia. Diabetes, Obesity and Metabolism, 2005; 7 (4):406-413. 
(106) Sarvazyan AP, Rudenko OV, Swanson SD, Fowlkes JB, Emelianov SY. Shear wave elasticity imaging: a new ultrasonic technology of medical diagnostics. Ultrasound Med Biol, 1998; 24 (9):1419-1435.

(107) Burstein AH, Reilly DT, Martens M. Aging of bone tissue: mechanical properties. Journal of bone and joint surgery American volume, 1976; 58 (1):82-86.

(108) Yamada H, Evans FG. Strength of biological materials. Baltimore, Maryland, USA: Williams \& Wilkins, 1970.

(109) Rohlmann A, Zilch H, Bergmann G, Kolbel R. Material properties of femoral cancellous bone in axial loading. Arch Orthop Trauma Surg, 1980; 97 (2):95-102.

(110) Keaveny TM, Guo XE, Wachtel EF, McMahon TA, Hayes WC. Trabecular bone exhibits fully linear elastic behavior and yields at low strains. J Biomech, 1994; 27 (9):11271136.

(111) Fridén J, Lieber RL. Spastic muscle cells are shorter and stiffer than normal cells. Muscle Nerve, 2003; 27 (2):157-164.

(112) Vogel HG. Age dependance of mechanical and biochemical properties of skin, Part I: stress-strain experiments, skin thickness and biochemical analysis. Bioeng. Skin, 1987; 3:6791.

(113) Jacquemoud C, Bruyere-Garnier K, Coret M. Methodology to determine failure characteristics of planar soft tissues using a dynamic tensile test. J Biomech, 2007; 40 (2):468-475.

(114) Diridollou S, Patat F, Gens F, Vaillant L, Black D, Lagarde J, Gall Y, Berson M. In vivo model of the mechanical properties of the human skin under suction. Skin Research and technology, 2001; 6 (4):214-221.

(115) Carter DR, Hayes WC. The compressive behavior of bone as a two-phase porous structure. The Journal of bone and joint surgery American volume, 1977; 59 (7):954-977.

(116) Ciarelli M, Goldstein S, Dickie D, Ku J, Kapper M, Stanley J, Flynn M, Matthews L. Experimental determination of the orthogonal mechanical properties, density, and distribution of human trabecular bone from the major metaphyseal regions utilizing materials testing and computed tomography. Transactions of the Orthopaedic Research Society, 1986:42.

(117) Zil'bergleit A, Zlatina I, Sinyakov V, Khaikova M. A method of measuring the modulus of elasticity of human muscle tissue. Bull Exp Biol Med, 1983; 96 (6):1781-1785.

(118) Van Houten EEW, Doyley MM, Kennedy FE, Weaver JB, Paulsen KD. Initial in vivo experience with steady-state subzone-based MR elastography of the human breast. Journal of Magnetic Resonance Imaging, 2003; 17 (1):72-85.

(119) Erdemir A, McLean S, Herzog W, van den Bogert AJ. Model-based estimation of muscle forces exerted during movements. Clin Biomech, 2007; 22 (2):131-154. 
(120) Samani A, Plewes D. A method to measure the hyperelastic parameters of ex vivo breast tissue samples. Phys Med Biol, 2004; 49 (18):4395-4405.

(121) Geerligs M, Van Breemen L, Peters G, Ackermans P, Baaijens F, Oomens C. In vitro indentation to determine the mechanical properties of epidermis. J Biomech, 2011; 44 (6):1176-1181.

(122) Delalleau A, Josse G, Lagarde JM, Zahouani H, Bergheau JM. A nonlinear elastic behavior to identify the mechanical parameters of human skin in vivo. Skin Research and Technology, 2008; 14 (2):152-164.

(123) Ní Annaidh A, Bruyère K, Destrade M, Gilchrist MD, Otténio M. Characterization of the anisotropic mechanical properties of excised human skin. Journal of the Mechanical Behavior of Biomedical Materials, 2012; 5 (1):139-148.

(124) McElhaney JH. Dynamic response of bone and muscle tissue. J Appl Physiol, 1966; 21 (4):1231-1236.

(125) Van Sligtenhorst C, Cronin DS, Wayne Brodland G. High strain rate compressive properties of bovine muscle tissue determined using a split Hopkinson bar apparatus. J Biomech, 2006; 39 (10):1852-1858.

(126) Song B, Chen W, Ge Y, Weerasooriya T. Dynamic and quasi-static compressive response of porcine muscle. J Biomech, 2007; 40 (13):2999-3005.

(127) Chawla A, Mukherjee S, Marathe R, Karthikeyan B and Malhotra R. Determining Strain Rate Dependence of Human Body Soft Tissues Using a Split Hopkinson Pressure Bar. International IRCOBI Conference on the Biomechanics of Impact, 20-22 September, Madrid, Spain, 2006. 173-182

(128) Haut R. The effects of orientation and location on the strength of dorsal rat skin in high and low speed tensile failure experiments. J Biomech Eng, 1989; 111 (2):136-140.

(129) Dombi GW, Haut RC, Sullivan WG. Correlation of high-speed tensile strength with collagen content in control and lathyritic rat skin. J Surg Res, 1993; 54 (1):21-28.

(130) Shergold OA, Fleck NA, Radford D. The uniaxial stress versus strain response of pig skin and silicone rubber at low and high strain rates. Int J Impact Eng, 2006; 32 (9):13841402.

(131) Lim J, Hong J, Chen WW, Weerasooriya T. Mechanical response of pig skin under dynamic tensile loading. Int J Impact Eng, 2011; 38 (2):130-135.

(132) Comley K, Fleck N. The mechanical response of porcine adipose tissue. ASME Journal of Biomechanical Engineering, 2009. Available at: [http://www-

mech.eng.cam.ac.uk/profiles/fleck/papers/259.pdf ] Accessed Feb. 8, 2013.

(133) Clemmer J, Liao J, Davis D, Horstemeyer MF, Williams LN. A mechanistic study for strain rate sensitivity of rabbit patellar tendon. J Biomech, 2010; 43 (14):2785-2791. 
(134) Heiner AD. Structural properties of fourth-generation composite femurs and tibias. J Biomech, 2008; 41 (15):3282-3284.

(135) Chong A, Miller F, Buxton M, Friis EA. Fracture toughness and fatigue crack propagation rate of short fiber reinforced epoxy composites for analogue cortical bone. $\mathrm{J}$ Biomech Eng, 2007; 129 (4):487-493.

(136) Gardner MP, Chong ACM, Pollock AG, Wooley PH. Mechanical evaluation of largesize fourth-generation composite femur and tibia models. Ann Biomed Eng, 2010; 38 (3):613-620.

(137) Sellier KG, Kneubuehl BP. Wound ballistics and the scientific background: Elsevier Science Health Science div, 1994.

(138) Fackler ML. Ordnance gelatin for ballistic studies: Detrimental effect of excess heat used in gelatin preparation. Am J Forensic Med Pathol, 1988; 9 (3):218-219.

(139) McHenry RR. Analysis of the dynamics of automobile passenger restraint systems. American Association for Automotive Medicine Annual Conference, Cornell Aeronautical Laboratory, Inc., 1963.

(140) Lee D, Glueck M, Khan A, Fiume E, Jackson K. A survey of modeling and simulation of skeletal muscle. ACM Transactions on Graphics, 2009; 28 (4), Article 106. DOI 10.1145/1559755.1559763

(141) Oomens C, Maenhout M, Van Oijen C, Drost M, Baaijens F. Finite element modelling of contracting skeletal muscle. Philosophical Transactions of the Royal Society of London Series B: Biological Sciences, 2003; 358 (1437):1453-1460.

(142) Ambrósio JAC, Pereira MFOS, da Silva FP. Crashworthiness of transportation systems: structural impact and occupant protection: Kluwer Academic Pub, 1997.

(143) McKee N, Agur A, Tsang W and Singh K. Imagining What 3-D Computer Modelling of Muscle Offers Reconstructive Surgeons. III Congress of the World Society for Reconstructive Microsurgery - WSRM, 23-25 October 2005, Buenos Aires, Argentina, 2005. 60-62.

(144) Horsman MDK, Koopman H, Veeger H, van der Helm F. The Twente Lower Extremity Model: a comparison of maximal isometric moment with the literature. Enschede, The Netherlands: Gildeprint Drukkerijen, 2007.

(145) Tsirakos D, Baltzopoulos V, Bartlett R. Inverse optimization: functional and physiological considerations related to the force-sharing problem. Crit Rev Biomed Eng, 1997; 25 (4-5):371-407.

(146) Anderson FC, Pandy MG. A dynamic optimization solution for jumping in three dimensions. Computer Methods in Biomechanics \& Biomedical Engineering, 1999; 2 (3):201-231. 
(147) Glitsch U, Baumann W. The three-dimensional determination of internal loads in the lower extremity. J Biomech, 1997; 30 (11-12):1123-1131.

(148) Brand RA, Crowninshield RD, Wittstock C, Pedersen D, Clark CR, Van Krieken F. A model of lower extremity muscular anatomy. J Biomech Eng, 1982; 104 (4):304-310.

(149) Heller M, Bergmann G, Deuretzbacher G, Dürselen L, Pohl M, Claes L, Haas N, Duda G. Musculo-skeletal loading conditions at the hip during walking and stair climbing. J Biomech, 2001; 34 (7):883-893.

(150) An K, Takahashi K, Harrigan T, Chao E. Determination of muscle orientations and moment arms. J Biomech Eng, 1984; 106 (3):280-282.

(151) Pedersen DR, Brand RA, Davy DT. Pelvic muscle and acetabular contact forces during gait. J Biomech, 1997; 30 (9):959-965.

(152) Li G, Kaufman K, Chao E, Rubash H. Prediction of antagonistic muscle forces using inverse dynamic optimization during flexion/extension of the knee. J Biomech Eng, 1999; 121 (3):316-322.

(153) Zajac FE. Muscle and tendon: properties, models, scaling, and application to biomechanics and motor control. Crit Rev Biomed Eng, 1989; 17 (4):359-411

(154) Yang KH, Hu J, White NA, King AI, Chou CC, Prasad P. Development of numerical models for injury biomechanics research: a review of 50 years of publications in the Stapp Car Crash Conference. Stapp Car Crash J, 2006; 50: 429-490.

(155) Nigg BM, Herzog W. Biomechanics of the musculo-skeletal system: Wiley, New York, 1999.

(156) Cowin SC. Bone mechanics. 2nd Edition, Boca Raton, FL: CRC Press, 2001.

(157) Fick A, Weber E. Anatomisch-mechanische Studie ueber die Schultermuskeln I. Verhandl.Würz.Phys.Med.Ges, 1877; 11:123-153.

(158) Bischoff E. Einige Gewichts-und Trocken-Bestimmungen der Organe des menschlichen Korpers. Ztschr.f.rat.Med, 1863; 20 (75-118):472.

(159) Theile FW, His W. Gewichtsbestimmungen zur Entwickelung des Muskelsystem und des Skelettes beim Menschen. 1884.

(160) Murray WM, Buchanan TS, Delp SL. The isometric functional capacity of muscles that cross the elbow. J Biomech, 2000; 33 (8):943-952.

(161) Davis J, Kaufman KR, Lieber RL. Correlation between active and passive isometric force and intramuscular pressure in the isolated rabbit tibialis anterior muscle. J Biomech, 2003; 36 (4):505-512.

(162) Wickiewicz TL, Roy RR, Powell PL, Edgerton VR. Muscle architecture of the human lower limb. Clin Orthop Relat Res, 1983; Oct(179):275-283. 
(163) Delp SL, Loan JP, Hoy MG, Zajac FE, Topp EL, Rosen JM. An interactive graphicsbased model of the lower extremity to study orthopaedic surgical procedures. Biomedical Engineering, IEEE Transactions on, 1990; 37 (8):757-767.

(164) Pierrynowski MR, Allard P, Stokes IAF, Blanch JP. Analytical representation of muscle line of action and geometry. In: Three-Dimensional Analysis of Human Movement. (eds. Allard P, Stokes IAF, Blanch JP) Champaign, IL, Human Kinetics; 1995. p. 214-256.

(165) Vezin P and Verriest JP. Development of a set of numerical human models for safety. Proceedings of The 19th. International Technical Conference on the Enhanced Safety of Vehicles (ESV), 6-9 June, 2005, Washington DC, USA, 2005. 6-9.

(166) Esat II, Ozada N. Articular human joint modelling. Robotica, 2010; 28 (02):321-339.

(167) Assassi L, Charbonnier C, Schmid J, Volino P, Magnenat-Thalmann N. From MRI to anatomical simulation of the hip joint. Computer Animation and Virtual Worlds, 2009; 20 (1):53-66.

(168) Ackerman MJ. The visible human project. Proc IEEE, 1998; 86 (3):504-511.

(169) Silvestri C, Ray M. Development of a finite element model of the knee-thigh-hip of a 50th percentile male including ligaments and muscles. International Journal of crashworthiness, 2009; 14 (2):215-229.

(170) Gilles B, Moccozet L, Magnenat-Thalmann N. Anatomical modelling of the musculoskeletal system from MRI. Med Image Comput Comput Assist Interv, 2006; 4190 :289-296.

(171) Teran J, Sifakis E, Blemker SS, Ng-Thow-Hing V, Lau C, Fedkiw R. Creating and simulating skeletal muscle from the visible human data set. IEEE Trans Visual Comput Graphics, 2005; 11 (3):317-328.

(172) Blemker SS, Delp SL. Three-dimensional representation of complex muscle architectures and geometries. Ann Biomed Eng, 2005; 33 (5):661-673.

(173) Aubel A and Thalmann D. Interactive modeling of the human musculature. The Fourteenth Conference on Computer Animation. 7-8 Nov 2001, Seoul, South Korea, IEEE, 2001.167-255.

(174) Pappas GP, Asakawa DS, Delp SL, Zajac FE, Drace JE. Nonuniform shortening in the biceps brachii during elbow flexion. J Appl Physiol, 2002; 92 (6):2381-2389.

(175) McVeigh, E. \& Blemker, S. Real-time measurements of knee muscle moment arms during dynamic knee flexion-extension motion. Journal of Biomechanics, 2006; 3 (2):3619.

(176) Heemskerk AM, Strijkers GJ, Vilanova A, Drost MR, Nicolay K. Determination of mouse skeletal muscle architecture using three-dimensional diffusion tensor imaging. Magnetic resonance in medicine, 2005; 53 (6):1333-1340. 
(177) Asakawa DS, Blemker SS, Gold GE, Delp SL. In vivo motion of the rectus femoris muscle after tendon transfer surgery. J Biomech, 2002; 35 (8):1029-1037.

(178) Hertz H. On the Contact of Rigid Elastic Solids and on Hardness. New York: MacMillan, 1882.

(179) Kaufman DM, Sueda S, James DL, Pai DK. Staggered projections for frictional contact in multibody systems. ACM Transactions on Graphics (TOG), 2008; 27 (5):164-175

(180) Johnson KL. Contact mechanics. Cambridge, UK: Cambridge Univ Press, 1987.

(181) Kikuchi N, Oden JT. Contact problems in elasticity: a study of variational inequalities and finite element methods. Volume 8, Philadelphia, Pennsylvania, USA: Society for Industrial Mathematics, 1988.

(182) Brogliato B. Nonsmooth mechanics: models, dynamics, and control. New York: Springer Verlag, 1999.

(183) Wriggers P. Computational contact mechanics: Wiley: New York. 2006.

(184) Stewart DE. Rigid-body dynamics with friction and impact. SIAM Rev, 2000; 41 (1):339.

(185) Drumwright E. A fast and stable penalty method for rigid body simulation.

Visualization and Computer Graphics, IEEE Transactions on, 2008; 14 (1):231-240.

(186) Lin MC, Manocha D. Collision and proximity queries. In: Handbook of Discrete and Computational Geometry, 2003. Available at:

[https://wwwx.cs.unc.edu/ geom/papers/documents/articles/2003/lin03.pdf] Accessed: $8^{\text {th }}$ February 2013.

(187) Delp SL, Anderson FC, Arnold AS, Loan P, Habib A, John CT, Guendelman E, Thelen DG. OpenSim: open-source software to create and analyze dynamic simulations of movement. Biomedical Engineering, IEEE Transactions on, 2007; 54 (11):1940-1950.

(188) Al Nazer R. Flexible Multibody Simulation Approach in the Dynamic Analysis of Bone Strains During Physical Activity. Journal of Biomechanics, 2008; 41 (5):1036-1043.

(189) Brown SHM, McGill SM. Co-activation alters the linear versus non-linear impression of the EMG-torque relationship of trunk muscles. J Biomech, 2008; 41 (3):491-497.

(190) Basmajian JV, De Luca CJ. Muscles alive: their functions revealed by electromyography. Williams and Wilkins: Baltimore, 1985.

(191) Tang YM, Hui KC. Simulating tendon motion with axial mass-spring system. Comput Graph, 2009; 33 (2):162-172.

(192) Hill AV. The heat of shortening and the dynamic constants of muscle. Proceedings of the Royal Society of London.Series B, Biological Sciences, 1938; 126 (843):136-195. 
(193) Huxley AF. Muscle structure and theories of contraction. Prog Biophys Biophys Chem, 1957; 7 :255-318.

(194) Hatze H. A myocybernetic control model of skeletal muscle. Biol Cybern, 1977; 25 (2):103-119.

(195) Böl M, Reese S. Micromechanical modelling of skeletal muscles based on the finite element method. Comput Methods Biomech Biomed Engin, 2008; 11 (5):489-504.

(196) Chao E, Armiger RS, Yoshida H, Lim J, Haraguchi N. Virtual interactive musculoskeletal system (VIMS) in orthopaedic research, education and clinical patient care. Journal of Orthopaedic Surgery and Research, 2007; 2 (2). DOI: 10.1186/1749-799X-2-2

(197) Semwal SK, Hallauer JJ. Biomechanical modeling: Implementing line-of-action algorithm for human muscles and bones using generalized cylinders. Comput Graph, 1994; 18 (1):105-112.

(198) Nussbaum MA, Chaffin DB, Rechtien CJ. Muscle lines-of-action affect predicted forces in optimization-based spine muscle modeling. J Biomech, 1995; 28 (4):401-409.

(199) Gatton M, Pearcy M, Pettet G. Modelling the line of action for the oblique abdominal muscles using an elliptical torso model. J Biomech, 2001; 34 (9):1203-1207.

(200) Pandy MG. Computer modeling and simulation of human movement. Annu Rev Biomed Eng, 2001; 3 (1):245-273.

(201) Dong F, Clapworthy GJ, Krokos MA, Yao J. An anatomy-based approach to human muscle modeling and deformation. IEEE Trans Visual Comput Graphics, 2002; 8 (2):154170.

(202) Badler NI, Smoliar SW. Digital representations of human movement. ACM Computing Surveys (CSUR), 1979; 11 (1):19-38.

(203) Magnenat-Thalmann N, Thalmann D. Synthetic actors in computer-generated 3D films: Springer-Verlag New York, Inc., 1990.

(204) Hardt DE. Determining muscle forces in the leg during normal human walking -an application and evaluation of optimization methods. J Biomech Eng, 1978; 100 (2):72-78.

(205) Hatze H. The complete optimization of a human motion. Math Biosci, 1976; 28 (12):99-135.

(206) Hoy MG, Zajac FE, Gordon ME. A musculoskeletal model of the human lower extremity: the effect of muscle, tendon, and moment arm on the moment-angle relationship of musculotendon actuators at the hip, knee, and ankle. J Biomech, 1990; 23 (2):157-169.

(207) Pierrynowski MR, Morrison JB. A physiological model for the evaluation of muscular forces in human locomotion: theoretical aspects. Math Biosci, 1985; 75 (1):69-101. 
(208) Jensen RH, Davy DT. An investigation of muscle lines of action about the hip: a centroid line approach vs the straight line approach. J Biomech, 1975; 8 (2):103-110

(209) Van der Helm FCT, Veenbaas R. Modelling the mechanical effect of muscles with large attachment sites: application to the shoulder mechanism. J Biomech, 1991; 24 (12):1151-1163.

(210) Chadwick JE, Haumann DR, Parent RE. Layered construction for deformable animated characters. ACM Siggraph Computer Graphics, 1989; 23 (3):243-252.

(211) Kraus C, Bock HG, Mutschler H. Parameter estimation for biomechanical models based on a special form of natural coordinates. Multibody System Dynamics, 2005; 13 (1):101-111.

(212) Eberhard P, Spägele T, Gollhofer A. Investigations for the dynamical analysis of human motion. Multibody System Dynamics, 1999; 3 (1):1-20.

(213) Nagano A, Yoshioka S, Komura T, Himeno R, Fukashiro S. A Three-Dimensional Linked Segment Model of the Whole Human Body. International Journal of Sport and Health Science, 2005; 3 (Special_Issue_2005):311-325.

(214) Delp SL, Loan JP. A graphics-based software system to develop and analyze models of musculoskeletal structures. Comput Biol Med, 1995; 25 (1):21-34.

(215) Delp SL, Loan JP. A computational framework for simulating and analyzing human and animal movement. Computing in Science \& Engineering, 2000; 2 (5):46-55.

(216) Damsgaard M, Rasmussen J, Christensen ST, Surma E, de Zee M. Analysis of musculoskeletal systems in the AnyBody Modeling System. Simulation Modelling Practice and Theory, 2006; 14 (8):1100-1111.

(217) Free SA, Delp SL. Trochanteric transfer in total hip replacement: Effects on the moment arms and force-generating capacities of the hip abductors. Journal of orthopaedic research, 1996; 14 (2):245-250.

(218) Yucesoy CA, Koopman BH, Huijing PA, Grootenboer HJ. Three-dimensional finite element modeling of skeletal muscle using a two-domain approach: linked fiber-matrix mesh model. J Biomech, 2002; 35 (9):1253-1262.

(219) Arnold AS, Salinas S, Hakawa DJ, Delp SL. Accuracy of muscle moment arms estimated from MRI-based musculoskeletal models of the lower extremity. Computer Aided Surgery, 2000; 5 (2):108-119.

(220) Cheung JTM, Zhang M, Leung AKL, Fan YB. Three-dimensional finite element analysis of the foot during standing-a material sensitivity study. J Biomech, 2005; 38 (5):1045-1054.

(221) Van Rietbergen B, Huiskes R, Eckstein F, Rüegsegger P. Trabecular bone tissue strains in the healthy and osteoporotic human femur. Journal of Bone and Mineral Research, 2003; 18 (10):1781-1788. 
(222) Ng-Thow-Hing V, Adviser-Fiume E. Anatomically-based models for physical and geometric reconstruction of humans and other animals.[dissertation], University of Toronto, Canada; 2001.

(223) Van Donkelaar C, Kretzers L, Bovendeerd P, Lataster L, Nicolay K, Janssen J, Drost M. Diffusion tensor imaging in biomechanical studies of skeletal muscle function. J Anat, 1999; 194 (1):79-88.

(224) Gielen AW, Oomens CW, Bovendeerd PH, Arts T, Janssen JD. A Finite Element Approach for Skeletal Muscle using a Distributed Moment Model of Contraction. Comput Methods Biomech Biomed Engin, 2000; 3 (3):231-244.

(225) Johansson T, Meier P, Blickhan R. A finite-element model for the mechanical analysis of skeletal muscles. J Theor Biol, 2000; 206 (1):131-149.

(226) Perillo-Marcone A, Alonso-Vazquez A, Taylor M. Assessment of the effect of mesh density on the material property discretisation within QCT based FE models: a practical example using the implanted proximal tibia. Computer Methods in Biomechanics \& Biomedical Engineering, 2003; 6 (1):17-26.

(227) Lin YC, Haftka RT, Queipo NV and Fregly BJ. Dynamic simulation of knee motion using three dimensional surrogate contact modeling. Proceedings of the ASME 2008 summer bioengineering conference. SBC, Marco Island, 25-29 June 2008, Florida, USA, 2008.

(228) Krosshaug T, Andersen T, Olsen OEO, Myklebust G, Bahr R. Research approaches to describe the mechanisms of injuries in sport: limitations and possibilities. Br J Sports Med, 2005; 39 (6):330-339. 


\section{Table of Figures}

Figure 1 - Autopsy of an Instrumented PMHS Lower Leg (Photos courtesy of Allen-Vanguard Corporation, testing conducted through the US LEAP program) $)^{38}$

Figure 2 - Lateral Dynamic Shear Testing Configuration "Reproduced by permission of The Stapp

Association." ${ }^{64}$ 19

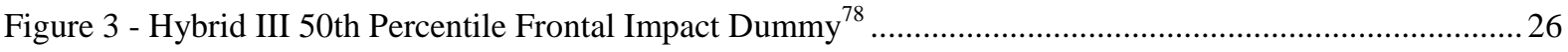

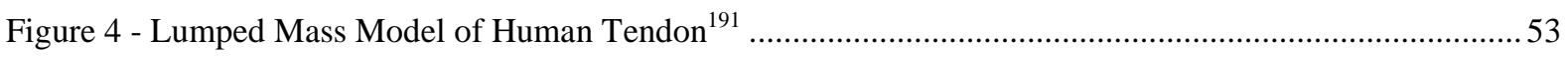

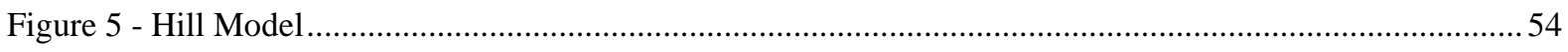

Figure 6 - FE Model of a Human Leg with Simulated Muscles and Ligaments ${ }^{169}$.......................................58

Table 1 - Estimations of the Conditions Experienced in 'In Play' Sport Impacts ..........................................9

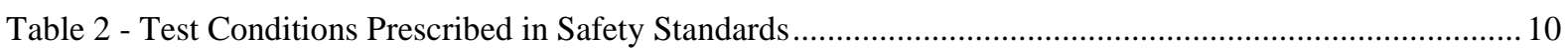

Table 3 - Anthropometric data displaying a subset of human body measurements for different demographic groups relative to the $50^{\text {th }}$ percentile US male dataset.

Table 4 - A Subset of Human Body Segmental Inertia Properties [Winter (1990) adapted from Dempster

Table 5 - Percentage Differences in Masses of Demographic Groups from $50^{\text {th }}$ Percentile US Male

Measurements

Table 6 - Percentage Differences in Moment of Inertia from 50th Percentile US Male Parameters

Table 7 - Density Values of Human Tissues

Table 8 - Ultimate Tensile Strength Values of Human Tissues 39

Table 9 - Young's Modulus Values of Human Tissues. 